\title{
Metamorphic grade and gradient from white K-micas of Na-mica bearing sedimentary rocks in the Mosquito Creek Basin, East Pilbara Craton, Western Australia
}

\author{
Hanan J. Kisch ${ }^{\mathrm{a}, *}$, Wouter Nijman ${ }^{\mathrm{b}}$ \\ a Department of Geological and Environmental Sciences, Ben-Gurion University of the Negev, P.O.B. 653, Beer-Sheva 84105, Israel \\ ${ }^{\mathrm{b}}$ Department of Sedimentology, Faculty of Geosciences, Utrecht University, Postbus 80021, 3508TA, The Netherlands
}

\section{A R T I C L E I N F O}

\section{Article history:}

Received 3 April 2009

Received in revised form 14 October 2009

Accepted 24 October 2009

\section{Keywords:}

Illite 'crystallinity'

Kübler index

Deconvolution

Na-mica

X-ray diffraction

Metamorphic grade

Metamorphic gradient

Mosquito Creek Formation

Pilbara

\begin{abstract}
A B S T R A C T
Shales and phyllites from the turbidite sequences of the $2.9 \mathrm{Ga}$ Mosquito Creek Formation of the East Pilbara, Western Australia contain varying amounts of paragonite and mixed Na-K micas (MNKMs), the $00 l \mathrm{X}$-ray diffraction reflections of which are unresolved from the $10-\AA \AA$ reflections, and only partly resolved from the 5- $\AA$ reflections of white K-mica (WKM). The Kübler index ('crystallinity'), the full width at half maximum (FWHM) of the WKM, obtained from these composite reflections by applying a three-peak deconvolution procedure, reveals a metamorphic zoning of the Mosquito Creek Formation. The highest, "epimetamorphic", grade occurs in the - largely Na-mica free - southern part, with lower, medium- to high-anchimetamorphic, grades in the central part, notably in a WSW-ENE anticlinal zone extending from Nullagine to the Blue Spec Mine. The Na-mica free metasediments of the Glen Herring Shale of the Fortescue Group, overlying the Mosquito Creek Formation to the W, show only a slightly lower metamorphic grade. The low $b_{0}$ lattice parameter of the WKMs indicates a very low metamorphic $\mathrm{P} / \mathrm{T}$ gradient. The Na-mica bearing metasediments of the Mosquito Creek Formation correspond to a kaolinitebearing protolith, strongly Al-enriched and K-depleted with respect to the presumably granitic-tonalitic source rock.
\end{abstract}

(c) 2009 Elsevier B.V. All rights reserved.

\section{Introduction}

The East Pilbara Craton of Western Australia contains some of the earliest known sedimentary rock successions on Earth. The Mosquito Creek (MC) Formation belongs to the first major clastic influx following the Early Archaean greenstone belt development. These sediments are best studied where preserved under conditions of low, sub-greenschist metamorphic grade. This makes them suitable for the analysis of $\mathrm{P} / \mathrm{T}$ gradients immediately after burial at shallow crustal levels. The purpose of this study is to establish the grade and the relative timing of metamorphism in the MC Basin using the Kübler index, KI, after the recommendations of Guggenheim et al. (2001) or 'crystallinity', the full width at half maximum (FWHM) of the $10-\AA$ and $5-\AA$ WKM reflections, and to obtain information on the $P / T$ gradient of this metamorphism using the $b_{0}$ parameter of the white WKMs.

\footnotetext{
* Corresponding author. Tel.: +972 864612 90; fax: +972 86472997.

E-mail addresses: kisch@bgu.ac.il (H.J. Kisch), wnijman@geo.uu.nl (W. Nijman).
}

\section{Geological setting}

The East Pilbara Terrane (EPT) consists of the ultramafic, mafic and intermediate volcanics, (volcano)clastic sediments, and cherts in greenstone belts surrounding granitoid complexes (Fig. 1). The greenstones and associated sediments belong to the Palaeoarchaean Pilbara Supergroup (Van Kranendonk et al., 2006). A striking change in rock composition occurs around $3.0 \mathrm{Ga}$ ago with the influx of huge amounts of quartzo-feldspathic sediments of the Mesoarchaean De Grey Supergroup (Van Kranendonk et al., 2006), to which the sediments belong of the Mosquito Creek (MC) Basin, exposed $\mathrm{E}$ of Nullagine in the east Pilbara.

The MC Basin is bounded to the northwest by the McPhee Dome, and to the northeast by the Yilgalong greenstone belt and granitoid complex. In the $S$, it is separated from the Kurrana granitoid complex (largely $>3287 \mathrm{Ma}$ ) by a shear zone. The block encloses the outcrop of the $2.9 \mathrm{Ga}$ MC Formation (cf. Hickman, 1975, p. 120), the fill of the MC Basin. The basin fill unconformably overlies a greenstone belt rock assemblage, and is unconformably overlain in the $\mathrm{W}$ and $\mathrm{E}$ by the Neoarchaean (2765-2629 Ma) Fortescue Group. The geological setting of the MC Formation is variously interpreted: for instance as a passive margin along the EPT (Bagas et al., 2008) or as the terminal 

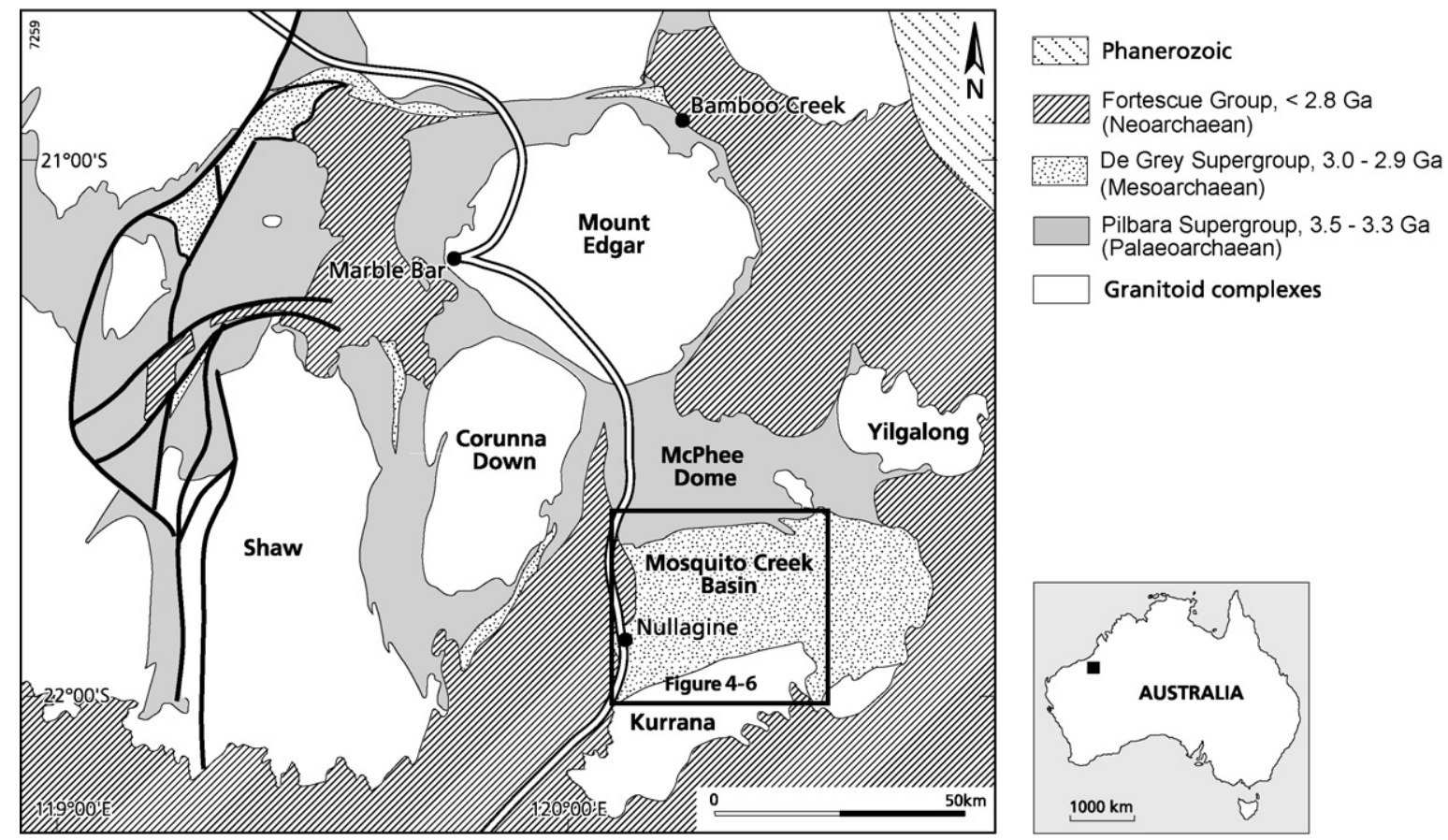

Fig. 1. Geological sketch map showing the setting of the Mosquito Creek Block in the East Pilbara Terrane (EPT) (after Van Kranendonk et al., 2006).

stage of a subsiding greenstone belt between rising granitoid complexes within the EPT (Hickman, 1984; Nijman et al., submitted for publication).

The following brief description is mainly based on the latter publication involving a modification of the stratigraphical nomenclature and interpretation of Bagas (2005) and Bagas et al. (2004a, 2008). The stratigraphical and tectonostratigraphical units are indicated on the maps (Figs. 4-6). The MC Formation consists of a central sequence of shale and turbidite, rimmed along the southern and northern margins by alluvial fan(delta) sandstone and conglomerate. This north-south facies distribution shows that an almost complete cross-section of the sedimentary basin fill is comprised within the block boundaries. A prominent slump unit is situated in the strike-parallel basin axis E of Nullagine. The MC Formation has been dated at 2932-2905 Ma (Bagas et al., 2004b) and placed within the De Grey Supergroup (Bagas, 2005; Van Kranendonk et al., 2006).

The MC Formation is folded into E-W striking folds that are accompanied by several thrusts, e.g. the Blue Spec Thrust. To the south, the MC Formation is adjoined by, and locally unconformable on, the Middle Creek Shear Zone and a 1-6 km broad tectonostratigraphical Kurrana Marginal Domain (Nijman et al., submitted for publication). This domain is composed of a folded, lithologically diverse rock suite including elements of the MC Formation and of a range of older units including the pale green (chloritic), strongly cleaved metasandstone ... interleaved with chloritic siltstone, chlorite-actinolite schist, phyllite, and rare amphibolite of the newly defined Coondamar Formation (Bagas, 2005, pp. 16-17). The Kurrana Shear Zone separates this domain from the southerly adjacent Kurrana granitoid complex, which contains the 3199-3178 Ma (Bagas, 2005, p. 16) Golden Eagle Orthogneiss and the post-tectonic ca. 2838 Ma Bonny Downs Granite.

In the southwest, the conglomeratic Dromedary Conglomerate of the MC Formation (Nijman et al., submitted for publication) unconformably overlies a unit of metasandstones and metashales, the Cajuput Spring Sandstone (Nijman et al., submitted for publication) of the De Grey Supergroup.
In the north, the MC Formation is also underlain by a clastic rock succession, the Cooke Creek unit of Nijman et al. (submitted for publication). These clastic sediments overlie in places strongly deformed stratigraphically diverse greenstone belt rocks of the Kelly and Warrawoona Groups of the McPhee Dome and the Mt. Elsie greenstone belt.

The MC Formation is discordantly overlain by sandstone and shale (the Glen Herring Shale) of the Hardey Formation of the Neoarchaean Fortescue Group.

Close to its northern margin, the Mosquito Creek block is intruded by the quartz syenite to quartz monzodiorite body of the Paleoproterozoic Bridget Suite (Bagas, 2005, p. 25), dated at $1803 \pm 19 \mathrm{Ma}$ (Nelson, 2002); prismatic porphyroblasts of probable chloritoid are common in slates from the contact aureole in the roof of this body.

\section{Samples collected}

One or more samples were collected from ca. 120 sampling stations, situated mainly along four profiles:

(1) A N-S profile along Nullagine River from ca. $21^{\circ} 43^{\prime} \mathrm{S}$ through Nullagine to the southern margin of the MC Formation at ca. $21^{\circ} 59^{\prime} \mathrm{S}$, with a southeastern branch along Five Mile Creek to the southern margin of the MC Formation at ca. $21^{\circ} 58^{\prime} \mathrm{S}$.

(2) A NE-SW profile in the Middle Creek area from the Blue Spec Mine at $21^{\circ} 49^{\prime} \mathrm{S}$ to $21^{\circ} 53^{\prime} \mathrm{S}$, NW of Nullagine Airport.

(3) Along Twenty Mile Creek from ca. $21^{\circ} 48^{\prime} \mathrm{S}$ to the southern margin of the MC Formation at $21^{\circ} 52^{\prime} \mathrm{S}$; and

(4) In the Cooke Creek-Mosquito Creek area from the northern margin of the MC Formation at ca. $21^{\circ} 41^{\prime} \mathrm{S}$ to $21^{\circ} 47^{\prime} \mathrm{S}$.

Additional scattered samples were collected between these profiles, notably in the Billjim Mining Centre-Mountain Maid Mine area. 

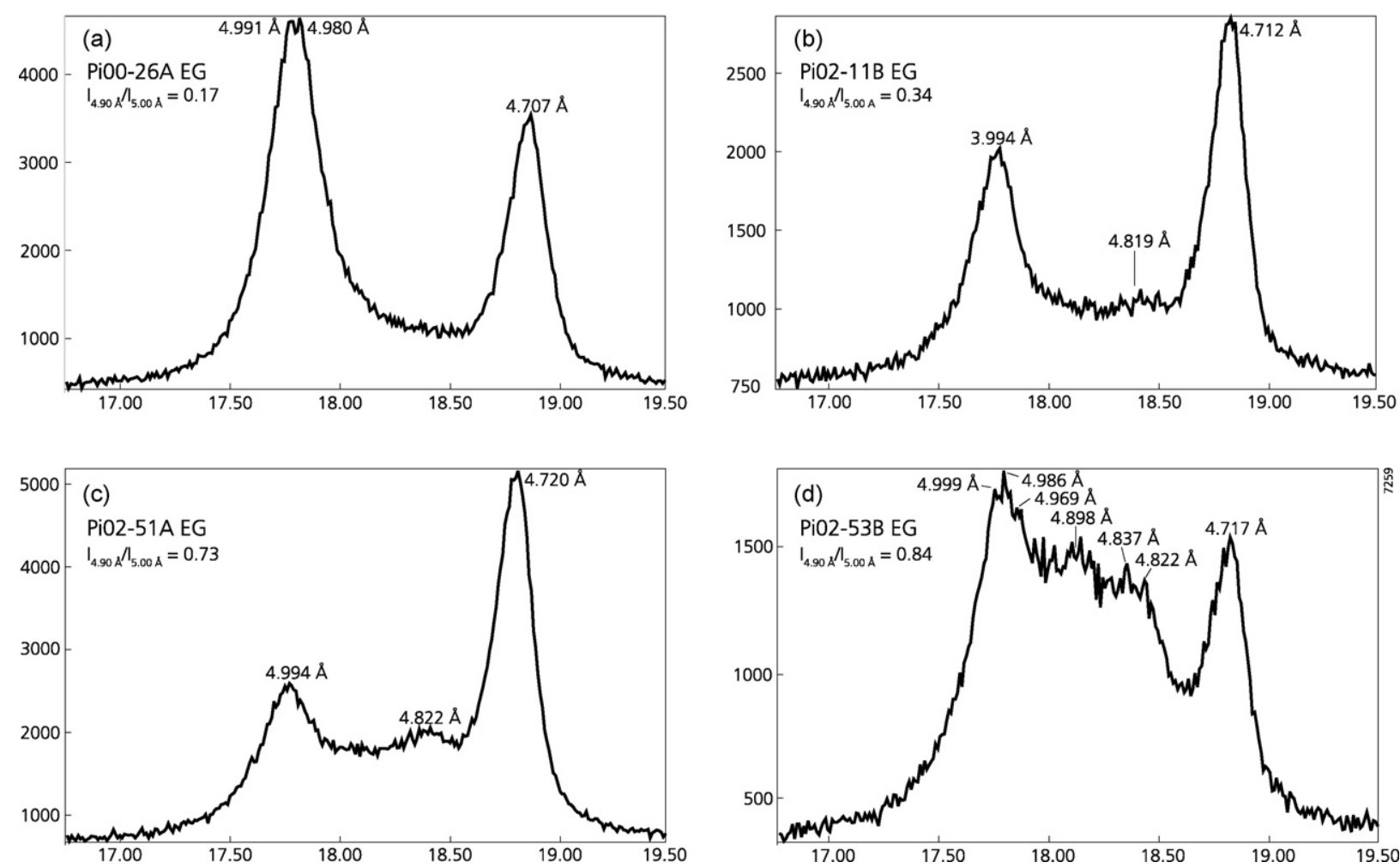

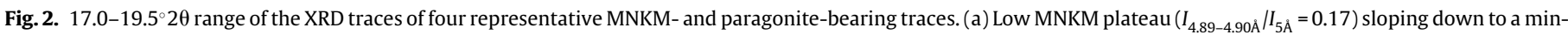

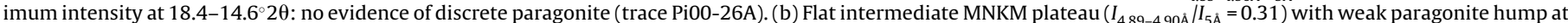

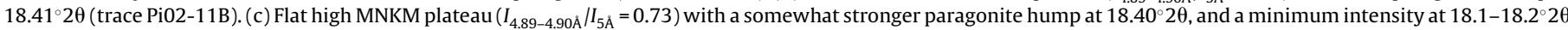

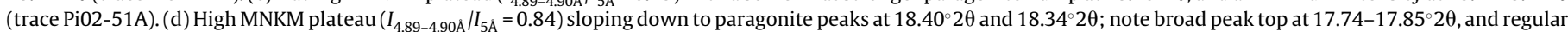
MNKM peak at $18.11^{\circ} 2 \theta \mathrm{K} \alpha / 4.90 \AA$. . This sample also shows a marked regular MNKM peak at $46.346^{\circ} 2 \theta \mathrm{K}_{1} / 1.9574 \AA$, equivalent to $4.89 \AA$ (trace Pi02-53B).

\section{Methods of study}

\subsection{Preparation and measurement}

Samples were ground, size-separated, acid-treated, Casaturated, and the $<2 \mu \mathrm{m}$ fraction pipetted on glass slides and X-rayed using the methods recommended by Kisch (1991) using copper radiation.

In the first instance, the X-ray traces were registered on strip charts, generally from $4^{\circ}$ to $23^{\circ} 2 \theta$ at $1^{\circ} 2 \theta=10 \mathrm{~mm}$ on the charts, and with slow scans from $7^{\circ}$ to $10^{\circ} 2 \theta$ at $1^{\circ} 2 \theta=40 \mathrm{~mm}$ on the chart. The full width at half maximum (FWHM) of the composite $10-\AA$ and 5- $\AA$ WKM reflections was measured on these slow scans.

In further stages of the study, when it became clear that most of the samples contained Na-rich micas and required peak fitting in order to recover FWHM of the WKM component, the traces including all traces of EG-solvated slides - were only registered on the computer base in order to allow peak fitting. Runs were made either from $7^{\circ}$ to $22^{\circ} 2 \theta$ at counting intervals of $0.035^{\circ} 2 \theta$ - in order to include the mica $00 \mathrm{l}$ peaks at $5.00-4.82 \AA\left(17.74-18.40^{\circ} 2 \theta\right)$, and the quartz peak at $4.255 \AA\left(20.86^{\circ} 2 \theta\right)$ - and with slow scans from $7^{\circ}$ to $10^{\circ} 2 \theta$ or from $7^{\circ}$ to $22^{\circ} 2 \theta$, both at counting intervals of $0.010^{\circ} 2 \theta$.

Presence of paragonite is indicated by its 004 and 006 reflections at $4.82 \AA\left(18.40^{\circ} 2 \theta\right)$ and $3.21 \AA\left(27.79^{\circ} 2 \theta\right)$ - the latter masked by the strong $3.194 \AA\left(27.9^{\circ} 2 \theta\right)$ reflection of albite, if present -, and by a high-angle shoulder on the $10-\AA$ WKM peak; the height of this shoulder relative to that of the $10-\AA \AA$ is usually higher by up to $30 \%$ than that of the paragonite peak at 4.82 A to that of the WKM peak at $5 \AA$. The paragonite peak at $18.40^{\circ} 2 \theta$ is often poorly resolved from the chlorite 003 peak at ca. $18.81^{\circ} 2 \theta$ (e.g. Fig. $2 b$ and c), reflecting poor 'crystallinity' of paragonite and conveivably presence of a margarite reflection at ca. $4.78 \AA$ ( $\left.18.56^{\circ} 2 \theta\right)$ (cf. Livi et al., 1997, Fig. 11).
Presence of MNKMs $^{1}$ is evident from a distinct MNKM "plateau" at $5.00-4.82 \AA\left(17.74-18.40^{\circ} 2 \theta \mathrm{K} \alpha\right)$ or a high-angle tail to the $5 \AA$ $\left(17.74^{\circ} 2 \theta \mathrm{K} \alpha\right)$ WKM peak.

The 17.0-19.5 $2 \theta$ range of the traces of four representative MNKM- and paragonite-bearing traces is shown in Fig. 2.

Discrete peaks at $3.25-3.26 \AA\left(27.35-27.45^{\circ} 2 \theta \mathrm{K} \alpha\right)$ - masked by the strong $3.25 \AA(27.42 \theta)$ reflection of K-feldspar, if present and $1.954-1.960 \AA$ ( $\left.46.43-46.28^{\circ} 2 \theta \mathrm{K} \alpha\right)$ and less common, weaker reflections at $4.875-4.905 \AA\left(18.08-18.20^{\circ} 2 \theta \mathrm{K} \alpha\right)$ indicate the presence of regular MNKMs with $\mathrm{Na} / \mathrm{K}$ mica ratios of ca. 65/35 to 60/40.

The traces of a few EG-solvated samples show a broad peak at approximately $8^{\circ} 2 \theta(11 \AA \AA)$ indicating long-range ordering $(R>1)$ of an illite/smectite mixed-layer, probably the $001 / 004^{*}$ reflection of a superstructure of a R3 (ISII) illite (0.9)/smectite (Moore and Reynolds, 1997, p. 272 and Fig. 8.7; Brown and Brindley, 1980, Fig. 4.25). In some other samples presence of such a reflection is suggested by a marked but weak low-angle tail to the 10 - $\AA$ WKM reflection. In a few samples, shoulders at ca. 15.2-15.7 $\AA$, shifting to ca. $17 \AA$ Apon EG solvation, indicate the presence of smectite, and a reflection at $3.57-3.59 \AA\left(24.8-24.95^{\circ} 2 \theta\right)$, well resolved from the chlorite reflection at 3.53-3.54 $\AA\left(25.15-25.2^{\circ} 2 \theta\right)$, that of kaolinite.

$d_{002}$ was determined from $d_{004}$ at ca. $5 \AA$, and from $d_{006}$ at ca. $3.33 \AA$ where it is sufficiently low to be resolved from the strong quartz reflection at $3.343 \AA$.

The $b_{0}$ lattice parameter of the WKM was determined from its composite $d_{060 / \overline{3} 31}$ reflection at ca. $1.495-1.500 \AA\left(62.0-61.8^{\circ} 2 \theta\right.$ $\left.\mathrm{CuK} \alpha_{1}\right)$, measured in runs from $59^{\circ}$ to $63^{\circ} 2 \theta$ on powders side-

\footnotetext{
1 We follow the recommendations of Livi et al. $(1997,2008)$ in referring to the $\mathrm{Na}-\mathrm{K}$ micas as 'mixed' $\mathrm{Na} / \mathrm{K}$ micas (MNKM).
} 
packed in sample holders, at counting intervals of $0.010^{\circ} 2 \theta$. Any shifts in the diffraction angle were corrected using the sharp quartz reflection at $1.5415 \AA\left(59.96^{\circ} 2 \theta \mathrm{CuK} \alpha_{1}\right)$. In a few cases, peak fitting with symmetric peaks and separate $\alpha_{2}$ was used to establish the precise position of the WKM $d_{060 /-331}$ reflection (a) in order to resolve the quartz reflection at $1.5415 \AA\left(59.96^{\circ} 2 \theta \mathrm{CuK \alpha} \alpha_{1}\right)$ used for calibration from the adjacent, poorly resolved low- $d$ 060 reflection of some Mg-rich chlorites at ca. $1.543-1.545 \AA$ (59.89-59.81 $\left.{ }^{\circ} 2 \theta \mathrm{CuK} \alpha_{1}\right)$, and (b) in order to establish the precise position of the WKM 060/-331 reflection when poorly resolved from that of paragonite at ca. 1.487-1.483 $\AA$ (62.4-62.6 $\left.2 \theta \mathrm{CuK \alpha}_{1}\right)$ in a broad-topped complex peak due to exceptionally high contents of MNKMs.

\subsection{Relative intensity of the MNKM "plateau"}

The intensities of the MNKM "plateau" between $17.74{ }^{\circ} 2 \theta(5.0 \AA)$ and $18.40^{\circ} 2 \theta(4.82 \AA)$, as measured at $18.1^{\circ} 2 \theta(4.89-4.90 \AA)$, relative to the intensity of the $5-\AA$ WKM peak at ca. $17.74^{\circ} 2 \theta$, $I_{\text {plateau } 4.89-4.90 \AA} / I_{5 \AA \AA}$, listed in Table 1 , show a reasonably linear positive correlation with the unfitted FWHM of the 10-Å peak (Fig. 3), and thus constitute an approximate indication of the content of Na-micas.

Very low intensity ratios $I_{4.89-4.90 \AA} / I_{5 \AA}$ of $<0.10$ in some traces indicate the virtual absence of Na-mica. Application of the three-peak deconvolution procedure to narrow peaks with FWHM $<0.20^{\circ} 2 \theta$ in such traces produces little or no further narrowing, but its application to the broader complex $10-\AA \AA$ peaks with $0.26-0.31^{\circ} 2 \theta$ in some traces - notably in samples from the Glen Herring Shale - produces $\mathrm{FWHM}_{10 \AA}$ values of $0.21-0.26^{\circ} 2 \theta$, narrower by some $0.04-0.08^{\circ} 2 \theta$.

\subsection{Deconvolution}

Deconvolution ("peak fitting") was carried out using the program WINFIT by Stefan Krumm (University of Erlangen/Nürnberg) on the slow scans of the EG-solvated slides (unless otherwise indi-

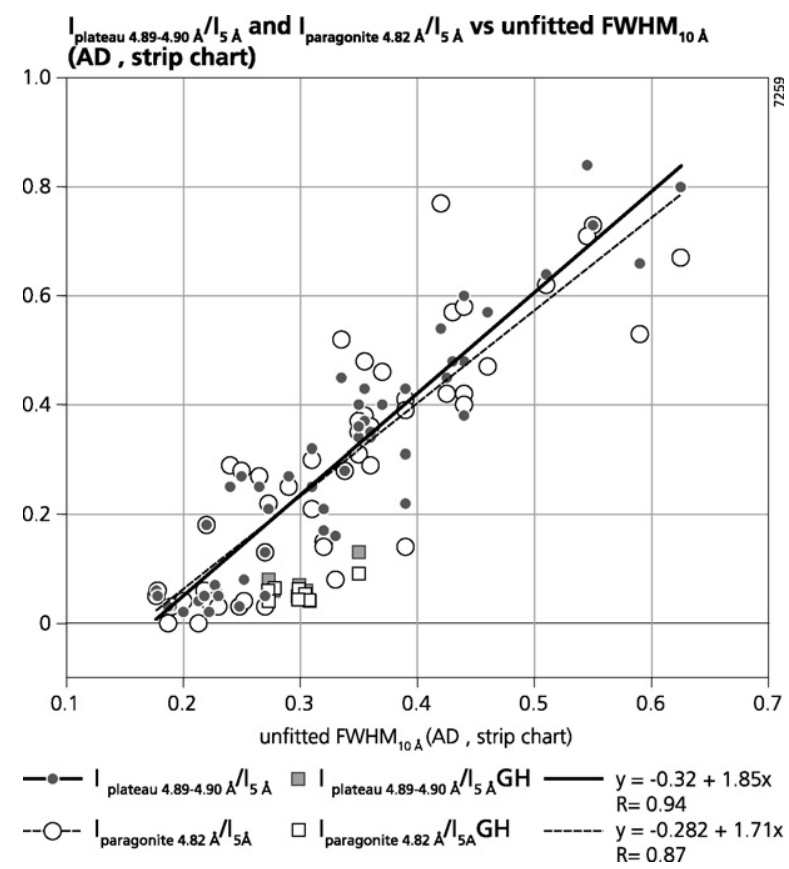

Fig. 3. Plot of the intensity ratios of the MNKM plateau at 4.89-4.90 $\AA$ (full symbols) and the paragonite reflection at $4.82 \AA$ (open symbols) to that of the WKM reflection at $5 \AA\left(I_{\text {plateau } 4.89-8.90 \AA} / I_{5 \AA}\right.$ and $\left.I_{\text {paragonite } 4.82 \AA} / I_{5 \AA}\right)$ versus the FWHM of the unfitted $10 \AA$ peak (strip charts, AD). Squares: samples from the Glen Herring Shale. cated), using asymmetric peaks in order to allow for asymmetry of the 10 - $\AA$ peak and for asymmetric distribution of the MPG compositions. WINFIT allows each selected component peak to be either locked at $\mathrm{a}^{\circ} 2 \theta$ position (hence: locked peaks), or to migrate freely within the $2 \theta$ range selected for fitting in order to obtain the highest reliability for the peak fit (hence: unlocked peaks).

\section{Deconvolution of the WKM peaks}

Deconvolution ("peak fitting") of the composite mica peaks in Na-mica bearing samples is intended to resolve as much as possible the peak-broadening effects of the Na-micas on the WKM peaks at $10-\AA ̊$ and $5-\AA \AA$, and thus approximate the FWHM of these peaks as they would be without presence of Na-rich micas, but without affecting the FWHM of the WKM in the Na-mica free samples. We find that two-peak deconvolutions of the 5 - $\AA$ peak with one unlocked peak to model both paragonite and MNKM (e.g. Battaglia et al., 2004) insufficiently account for either, notably in the presence of discrete paragonite, and give fits with broad $\mathrm{FWHM}_{5 \AA}{ }^{*}$ and poor reliabilities; as a standard procedure we therefore apply three-peak deconvolution with separate MNKM and paragonite peaks.

In such deconvolutions, the MNKM peaks should ideally be positioned so as to cover the MNKM contribution to the X-ray traces. It may be argued that the MNKM peak should be locked at a position equivalent to the "plateau" maximum at ca. $18.13^{\circ} 2 \theta(4.89 \AA)$ present in a few of the traces (cf. Fig. $2 \mathrm{~d}$ and possibly Fig. 2b), but most traces show no such maximum, and actually have a minimum at $18.1-18.4^{\circ} 2 \theta$ (cf. Fig. $2 \mathrm{a}$ and c). We have tried to attain an optimal position for the MNKM peaks by allowing the unlocked peaks to migrate to a best fit. However, upon repeated deconvolutions of the $17-19.5^{\circ} 2 \theta$ range of several traces, the unlocked peaks selected for the MNKM migrate to clusters at $2 \theta$ angles ranging from $18.13^{\circ}$ to $17.93^{\circ}$, in part dependent on the initial $2 \theta$ angle selected; in runs on many traces they will migrate partly or even exclusively to angles as low as $17.62-17.85^{\circ}$ - i.e. within $0.13^{\circ} 2 \theta$ of the WKM peak -, in particular when the MNKMs form a high-angle "tail" to the WKM reflection at $5 \AA$ (i.e. when the MNKMs are predominantly K-rich), resulting in marked weakening of the fitted WKM reflection and narrowing of its FWHM. Such migration to low angles could reflect the presence of reflections of illite/smectite mixed-layers (Stern et al., 1991; Wang et al., 1995; Jaboyedoff et al., 2000) or a poorly crystallized illite (Brime et al., 2002) on the low-angle side of a well-crystallized WKM reflection. As such I/S phases tend to be absent in anchimetamorphism (Jaboyedoff et al., 2000) or to disappear in mid-anchimetamorphism (Wang et al., 1995), they are unlikely to be of importance at the relatively high anchimetamorphic grade at which MNKM and paragonite are present (see also Battaglia et al., 2004, Table 1 in which I/S is reported only from the low-grade, "diagenetic" grades and questionable in association with MNKM). The low-angle tails are much lower than those shown by Brime et al. (2002, Fig. 1) and the "diagenetic" and low-grade anchizonal samples of Stern et al. (1991, Fig. 2), and four-peak deconvolutions with an extra unlocked "illite/smectite mixed-layer" peak at ca. 8.4-8.6 $2 \theta(10.8-10.3 \AA)$ on several traces with weak low-angle tails to the $10-\AA$ peak accordingly generate $\mathrm{FWHM}_{10 \AA}{ }^{*}$ values diverging little if at all from those fitted without such an extra peak. We have therefore waived further deconvolution of the WKM peak, except for the lowest-grade samples from the Glen Herring Shale (see below).

Adoption of a uniform setting of the MNKM positions for the deconvolutions admittedly implies the simplification that the weighted mean of the MNKM is the same for all samples, but avoids the scatter of the MNKM positions, and their migration to low angles. In order to compare WKM FWHM ${ }^{*}$ values fitted at uniform settings, we have therefore opted for three-peak deconvolutions with uniform locked peak positions for MNKM and paragonite, and 
Table 1

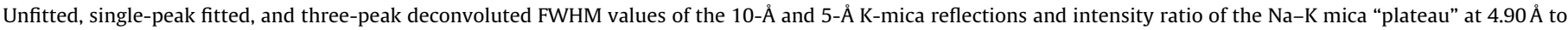
the $5-\AA$ peak reflections of the samples as arranged from $\mathrm{N}$ to $\mathrm{S}$ in five areas.

\begin{tabular}{|c|c|c|c|c|c|c|c|}
\hline \multirow[t]{3}{*}{ Sample number } & \multirow[t]{3}{*}{$\begin{array}{l}\text { Grid ref. to } \\
\text { nearest } 100 \mathrm{~m}\end{array}$} & \multicolumn{4}{|c|}{$\begin{array}{l}\text { FWHM }^{\circ} \Delta 2 \theta \text { unfitted from strip charts and } \\
\text { single-peak fits (slow scans) }\end{array}$} & \multirow{3}{*}{$\begin{array}{l}\text { Intensity ratio of } \\
\text { Na-K mica } \\
\text { "plateau" at } 4.90 \AA \\
\text { to } 5-\AA \text { peak }(\mathrm{AD})\end{array}$} & $\begin{array}{l}\mathrm{FWHM}^{*} \triangle \Delta 2 \theta(\mathrm{EG}) \text {, three-peak } \\
\text { deconvolution }\end{array}$ \\
\hline & & 10-Å peak & & 5-Å peak & & & $10 \AA ̊$ peak \\
\hline & & $\begin{array}{l}\text { Strip chart } \\
\text { (AD) }\end{array}$ & $\begin{array}{l}\text { Single-peak } \\
\text { fit (EG) }\end{array}$ & $\begin{array}{l}\text { Strip chart } \\
\text { (AD) }\end{array}$ & $\begin{array}{l}\text { Single-peak } \\
\text { fit }(E G)^{\mathrm{a}}\end{array}$ & & $\begin{array}{l}\text { Mixed Na-K mica (MNKM) } \\
\text { peak locked at }\end{array}$ \\
\hline
\end{tabular}

\begin{tabular}{|c|c|c|c|c|c|c|c|c|c|}
\hline & & & & & & & $9.005^{\circ} 2 \theta$ & $18.00^{\circ} 2 \theta$ & 18.065 \\
\hline \multicolumn{10}{|l|}{ Nullagine River profile } \\
\hline $00-31 \mathrm{~A}$ & $06.7-95.5$ & 0.31 & & & & & & & \\
\hline $00-31 B$ & & 0.33 & 0.31 & & 0.32 & 0.16 & 0.26 & 0.28 & 0.29 \\
\hline $02-82 B$ & $06.7-94.7$ & 0.270 & 0.27 & $0.23^{b}$ & 0.23 & 0.13 & 0.22 & 0.215 & 0.22 \\
\hline $02-83$ & $06.3-94.4$ & 0.270 & & $0.21^{b}$ & & 0.05 & & & \\
\hline $02-84$ & $05.8-93.6$ & & & & & & & & \\
\hline $02-85$ & 06.9-93.2 & & & & & & & & \\
\hline \multicolumn{10}{|l|}{ Taylor Creek } \\
\hline $02-22 B$ & $07.0-92.3$ & 0.508 & 0.56 & & & 0.64 & 0.23 & 0.265 & 0.275 \\
\hline $02-23 A-B$ & $06.8-91.6$ & 0.625 & $0.65 \mathrm{AD}$ & & & 0.80 & $0.24 \mathrm{AD}$ & 0.26 & 0.27 \\
\hline $02-21$ & $06.8-90.7$ & 0.360 & 0.43 & & & 0.34 & 0.22 & 0.245 & 0.25 \\
\hline $02-20 \mathrm{~A}$ & $07.3-89.8$ & 0.333 & $0.47 \mathrm{AD}$ & & & 0.45 & 0.215 AD & 0.205 & 0.21 \\
\hline $02-12$ & $07.0-88.5$ & 0.355 & 0.47 & & & 0.37 & 0.21 & 0.215 & 0.225 \\
\hline $02-11 \mathrm{~B}$ & $06.9-87.6$ & 0.348 & 0.43 & & & 0.34 & 0.205 & 0.22 & 0.23 \\
\hline $02-86$ & $05.2-85.0$ & 0.36 & 0.43 & & & 0.35 & 0.23 & 0.235 & 0.24 \\
\hline 05-4 (Glen Herring Shale) & $04.2 / 84.6$ & 0.273 & 0.285 & $0.23^{b}$ & 0.27 & 0.03 & 0.235 & 0.24 & 0.24 \\
\hline $02-89 \mathrm{~A}$ & $04.4-84.0$ & 0.37 & 0.43 & & & 0.40 & 0.27 & 0.275 & 0.28 \\
\hline 00-30A (Glen Herring shale) & $07.0-85.8$ & 0.26 & 0.27 & & 0.275 & 0.07 & 0.21 & 0.255 & 0.25 \\
\hline 00-30C (Glen Herring shale) & & 0.35 & 0.33 & & 0.325 & 0.14 & 0.27 & 0.285 & 0.29 \\
\hline 05-3 (Glen Herring shale) & $04.3 / 84.2$ & 0.305 & 0.30 & $0.25^{\mathrm{b}}$ & 0.28 & 0.06 & 0.25 & 0.25 & 0.27 \\
\hline 05-2A (Glen Herring shale) & $04.3 / 84.2$ & 0.273 & 0.275 & $0.23^{\mathrm{b}}$ & 0.28 & 0.06 & 0.23 & 0.245 & 0.27 \\
\hline 05-2B (Glen Herring shale) & & 0.277 & 0.28 & $0.25^{\mathrm{b}}$ & 0.28 & 0.06 & 0.24 & 0.24 & 0.25 \\
\hline 05-1A (Glen Herring shale) & $04.3 / 83.9$ & 0.307 & 0.29 & $0.25^{\mathrm{b}}$ & 0.29 & 0.04 & 0.255 & 0.27 & 0.275 \\
\hline 05-1B (Glen Herring shale) & & 0.308 & 0.29 & $0.24^{\mathrm{b}}$ & 0.28 & 0.05 & 0.24 & 0.255 & 0.275 \\
\hline 05-5 (Glen Herring shale) & $03.2 / 82.4$ & 0.298 & 0.32 & $0.26^{\mathrm{b}}$ & 0.32 & 0.07 & 0.22 & 0.255 & 0.26 \\
\hline $02-80$ & $05.8-81.5$ & 0.44 & 0.51 & & & 0.60 & 0.25 & 0.245 & 0.265 \\
\hline $00-27 \mathrm{~A}$ & $04.4-80.0$ & 0.39 & 0.39 & & 0.39 & 0.16 & 0.30 & 0.325 & 0.335 \\
\hline $00-27 B$ & & 0.32 & 0.315 & & 0.31 & 0.14 & 0.25 & 0.26 & 0.265 \\
\hline $00-28 \mathrm{~A}$ & $04.5-79.6$ & 0.39 & 0.51 & & 0.32 & 0.43 & 0.32 & 0.32 & 0.32 \\
\hline $00-28 B$ & & 0.44 & 0.45 & & & 0.48 & 0.25 & 0.265 & 0.285 \\
\hline $00-29 A$ & $04.5-80.0$ & 0.37 & 0.45 & & & 0.33 & 0.31 & 0.26 & 0.27 \\
\hline $00-26 \mathrm{~A}$ & $01.4-77.0$ & 0.32 & 0.33 & & 0.32 & 0.17 & 0.25 & 0.26 & 0.275 \\
\hline $00-26 B$ & & 0.25 & & & & 0.14 & & & \\
\hline $00-26 C$ & & 0.23 & & & & 0.15 & & & \\
\hline $00-26 \mathrm{D}$ & & 0.21 & & & & & & & \\
\hline \multicolumn{10}{|l|}{ Nullagine } \\
\hline $02-76 \mathrm{~A}$ & $05.0-76.7$ & 0.347 & $0.34 \mathrm{AD}$ & & & 0.40 & 0.17 AD & 0.215 & 0.23 \\
\hline $02-66 \mathrm{~A}$ & $04.2-75.2$ & 0.42 & 0.42 & & & 0.54 & 0.21 & 0.205 & 0.21 \\
\hline $02-67$ & $04.1-73.9$ & 0.355 & 0.40 & & & 0.43 & 0.20 & 0.20 & 0.21 \\
\hline $02-68$ & $03.7-71.2$ & 0.198 & 0.19 & $0.19^{b}$ & 0.19 & 0.02 & 0.185 & & 0.19 \\
\hline \multicolumn{10}{|l|}{ N Dromedary } \\
\hline 00-19 & 03.0-69.8 & 0.18 & & 0.17 & & 0.04 & & & \\
\hline $00-18 \mathrm{~A}$ & 02.9-69.9 & 0.19 & & 0.17 & & $<0.01$ & & & \\
\hline $00-18 B$ & & 0.18 & & 0.16 & & 0 & & & \\
\hline $00-18 C$ & & 0.17 & & 0.16 & & 0 & & & \\
\hline \multirow{2}{*}{\multicolumn{10}{|c|}{ Castle Hillc }} \\
\hline & & & & & & & & & \\
\hline $02-69 A$ & $02.1-68.7$ & 0.218 & & $0.18^{b}$ & & 0.05 & & & \\
\hline $00-20 A$ & $01.4-68.0$ & 0.19 & & 0.18 & & 0.30 & & & \\
\hline $00-20 \mathrm{C}$ & & 0.16 & & & & & & & \\
\hline $00-21 \mathrm{~A}$ & $01.4-67.8$ & 0.36 & 0.22 & & 0.21 & 0.14 & 0.215 & 0.205 & 0.205 \\
\hline \multicolumn{10}{|l|}{ Cajuput Spring Well ${ }^{\mathrm{C}}$} \\
\hline $02-71 \mathrm{~A}$ & $01.3-67.2$ & 0.17 & & $\mathbf{0 . 1 7}{ }^{\mathrm{b}}$ & & 0.05 & & & \\
\hline \multicolumn{10}{|l|}{ S Dromedary } \\
\hline $00-16$ & $05.6-68.7$ & 0.16 & & 0.17 & & 0.11 & & & \\
\hline \multicolumn{10}{|l|}{ Five Mile Creek profile } \\
\hline $02-75 A$ & 07.6-74.9 & 0.29 & 0.33 & & & 0.27 & 0.21 & 0.20 & 0.21 \\
\hline $02-74 \mathrm{~A}$ & $08.6-74.1$ & 0.22 & & $0.17^{b}$ & & 0.02 & & & \\
\hline $02-73 B$ & $09.4-72.7$ & 0.606 & & vw & & $\begin{array}{l}\text { vw 5-A } \\
\text { peak }\end{array}$ & & & \\
\hline \multicolumn{10}{|c|}{ Mount Daniel Mine (MDM on maps) } \\
\hline $02-72 A$ & $09.7-72.5$ & 0.48 & & vw & & $<0.1$ & & & \\
\hline $02-91 \mathrm{~A}$ & $09.9-71.6$ & 0.23 & & $0.20^{b}$ & & 0.05 & & & \\
\hline $02-92$ & $10.4-70.4$ & 0.253 & & $0.23^{b}$ & & 0.08 & & & \\
\hline $00-22 \mathrm{~A}$ & $11.6-72.9$ & 0.23 & & & & & & & \\
\hline $00-22 B$ & & - & & & & & & & \\
\hline
\end{tabular}


Table 1 (Continued)

\begin{tabular}{|c|c|c|c|c|c|c|c|c|c|}
\hline \multirow[t]{4}{*}{ Sample number } & \multirow[t]{4}{*}{$\begin{array}{l}\text { Grid ref. to } \\
\text { nearest } 100 \mathrm{~m}\end{array}$} & \multicolumn{4}{|c|}{$\begin{array}{l}\text { FWHM }^{\circ} \Delta 2 \theta \text { unfitted from strip charts and } \\
\text { single-peak fits (slow scans) }\end{array}$} & \multirow{4}{*}{$\begin{array}{l}\text { Intensity ratio of } \\
\text { Na-K mica } \\
\text { "plateau" at } 4.90 \AA \\
\text { to } 5-\AA \text { A peak (AD) }\end{array}$} & \multicolumn{3}{|c|}{$\begin{array}{l}\mathrm{FWHM}^{*} \circ \Delta 2 \theta(\mathrm{EG}), \text { three-peak } \\
\text { deconvolution }\end{array}$} \\
\hline & & \multicolumn{2}{|l|}{ 10-Å peak } & \multicolumn{2}{|l|}{ 5-Å peak } & & $10 \AA ̊$ peak & & $5 \AA$ peak \\
\hline & & \multirow[t]{2}{*}{$\begin{array}{l}\text { Strip chart } \\
\text { (AD) }\end{array}$} & \multirow[t]{2}{*}{$\begin{array}{l}\text { Single-peak } \\
\text { fit (EG) }\end{array}$} & \multirow[t]{2}{*}{$\begin{array}{l}\text { Strip chart } \\
\text { (AD) }\end{array}$} & \multirow[t]{2}{*}{$\begin{array}{l}\text { Single-peak } \\
\text { fit }(E G)^{\mathrm{a}}\end{array}$} & & \multicolumn{3}{|c|}{$\begin{array}{l}\text { Mixed Na-K mica (MNKM) } \\
\text { peak locked at }\end{array}$} \\
\hline & & & & & & & $9.005^{\circ} 2 \theta$ & $18.00^{\circ} 2 \theta$ & $18.065^{\circ} 2 \theta$ \\
\hline \multicolumn{10}{|c|}{ Middle Creek profile } \\
\hline \multicolumn{10}{|c|}{ Golden Spec/Blue Spec Mining Centre } \\
\hline $00-25 \mathrm{~A}$ & $18.3-84.2$ & 0.46 & 0.51 & & & 0.57 & 0.295 & 0.28 & 0.29 \\
\hline $00-25 C$ & & 0.59 & 0.56 & & & 0.66 & 0.225 & 0.285 & 0.295 \\
\hline $00-25 \mathrm{D}$ & & 0.43 & 0.445 & & & 0.41 & 0.26 & 0.25 & 0.26 \\
\hline 02-17B & $17.8-82.9$ & 0.28 & 0.33 & $0.28^{\mathrm{b}}$ & & 0.30 & 0.21 & 0.24 & \\
\hline $00-24 \mathrm{~A}$ & $16.3-82.2$ & 0.31 & 0.40 & & & 0.32 & 0.22 & 0.225 & 0.23 \\
\hline $00-24 B$ & & 0.39 & 0.44 & & & 0.31 & 0.265 & 0.26 & 0.26 \\
\hline $00-24 C$ & & 0.44 & 0.47 & & & 0.38 & 0.255 & 0.275 & 0.285 \\
\hline $02-64$ & $18.1-80.8$ & 0.42 & 0.44 & & & 0.50 & 0.18 & 0.215 & \\
\hline 02-16B & $14.8-80.2$ & 0.26 & 0.285 & $0.26^{\mathrm{b}}$ & 0.26 & 0.22 & 0.18 & 0.21 & \\
\hline $00-23 \mathrm{~A}$ & $14.9-78.7$ & 0.19 & 0.19 & & 0.18 & 0.03 & 0.18 & 0.18 & 0.18 \\
\hline $00-23 B$ & & 0.22 & 0.20 & & 0.185 & 0.06 & 0.20 & 0.18 & 0.18 \\
\hline $00-23 C$ & & 0.17 & & & & & & & \\
\hline $02-26$ & $14.2-76.2$ & 0.23 & 0.195 & $0.195^{\mathrm{b}}$ & 0.18 & 0.05 & 0.195 & 0.18 & \\
\hline $02-14 \mathrm{~A}$ & $13.3-76.6$ & 0.17 & 0.15 & $0.16^{\mathrm{b}}$ & 0.16 & 0.00 & 0.15 & 0.16 & \\
\hline $02-13 A$ & $12.5-76.0$ & 0.20 & 0.20 & $0.19^{\mathrm{b}}$ & 0.19 & 0.11 & 0.17 & 0.185 & \\
\hline \multicolumn{10}{|c|}{ Twenty Mile Creek profile } \\
\hline 02-19A/B & $22.8-88.0$ & 0.240 & 0.31 & & 0.24 & 0.25 & 0.175 & 0.185 & 0.19 \\
\hline $02-51 \mathrm{~A}$ & $23.3-87.0$ & 0.550 & 0.52 & & & 0.73 & 0.26 & 0.24 & 0.25 \\
\hline $02-31$ & $24.5-86.5$ & 0.338 & & $0.28^{b}$ & & 0.28 & $0.26 \mathrm{AD}$ & & \\
\hline \multicolumn{10}{|c|}{ Branchies Well (BW on maps) } \\
\hline $02-52 B$ & $24.0-85.6$ & 0.348 & 0.42 & & & 0.36 & 0.20 & 0.22 & 0.225 \\
\hline 02-53B & $24.5-84.5$ & 0.547 & 0.51 & & & 0.84 & 0.23 & 0.24 & 0.27 \\
\hline $02-56$ & $24.3-82.6$ & 0.313 & 0.36 & & 0.32 & 0.25 & 0.205 & 0.23 & 0.23 \\
\hline 02-58B & $25.6-81.1$ & 0.223 & & $0.23^{b}$ & & 0.07 & & & \\
\hline $02-59 A$ & $25.9-80.5$ & 0.267 & 0.33 & & 0.28 & 0.25 & 0.195 & 0.215 & 0.22 \\
\hline Road & & & & & & & & & \\
\hline \multicolumn{10}{|c|}{ Cooke Creek-Mosquito Creek profile } \\
\hline $02-37 A$ & $37.0-98.7$ & 0.223 & & $0.24^{\mathrm{b}}$ & 0.22 & 0.18 & 0.19 AD & 0.19 & 0.20 \\
\hline $02-38$ & $* * * *-98.2$ & 0.187 & & $0.18^{b}$ & & 0.03 & & & \\
\hline 02-39 & $38.3-97.6$ & 0.247 & 0.215 & & 0.21 & $<0.1$ & 0.22 & 0.21 & 0.21 \\
\hline $02-46$ & $32.2-95.2$ & 0.217 & & $0.20^{\mathrm{b}}$ & & 0.28 & & & \\
\hline $02-43$ & $36.5-93.8$ & 0.277 & 0.285 & $0.24^{\mathrm{b}}$ & 0.23 & 0.21 & 0.25 & 0.22 & 0.225 \\
\hline $02-47$ & $37.3-93.3$ & 0.177 & & $0.19^{b}$ & & 0.06 & & & \\
\hline $02-48$ & $37.3-92.6$ & 0.247 & 0.31 & & & 0.27 & 0.19 & 0.19 & 0.195 \\
\hline $02-50$ & $38.0-90.3$ & 0.428 & 0.43 & 0.26 & & 0.48 & 0.19 & 0.20 & 0.20 \\
\hline
\end{tabular}

sh, shoulder on high-angle tail to 5-Å K-mica reflection. ( $\bullet$ ) Discrete 006 regular Na/K mixed-layer mica peak at 3.25-3.26 $\AA$ (27.44-27.36 $2 \theta$ ).

Values used in the maps Figs. 4-6 indicated in bold type.

a Only for traces with $I_{4.90 \AA} / I_{5 \AA} \leq 0.25$.

b Reduced by an empirical $0.02^{\circ} \Delta 2 \theta$ from measurements on strip charts of rapid scans to slow-scan equivalents.

c Localities not shown on the maps.

usually unlocked peak positions for WKM. We will compare the result of these deconvolutions with those using unlocked MNKM peaks in a forthcoming paper (Kisch, in preparation).

Whereas locking of the MNKM peak is essential in preventing its migration into close vicinity of the WKM peak, leaving the WKM and paragonite peaks unlocked usually has only a minor effect on the FWHM values of the fitted WKM peaks. However, upon fitting of traces of samples poor in paragonite and Na-rich MNKMs (Fig. 2a), the unlocked paragonite peak also tends to migrate to ${ }^{\circ} 2 \theta$ angles lower than that of the (locked) MNKM peak. Such migration causes narrowing and weakening of the fitted WKM peak, and therefore should be avoided: when it occurs, it is preferable to either lock the paragonite peak in position, or to dispense with it altogether, and perform two-peak deconvolutions instead.

\subsection{Deconvolution procedure adopted}

For deconvolution of the composite 10-Å and 5- ̊ peaks, we have opted for a locking position for the MNKM positions respectively at the spacing of $0.5 / 0.5 \mathrm{Na}-\mathrm{K}$ mica, $9.82 \AA$, i.e. $9.005^{\circ} 2 \theta$, and at $18.00^{\circ} 2 \theta$ (the latter corresponds to a slightly more potassic MNKM). Larger ${ }^{\circ} 2 \theta$ angles would achieve insufficient removal of the broadening effect of Na-micas, and smaller ${ }^{\circ} 2 \theta$ angles would result in undue narrowing of the $\mathrm{FWHM}_{10 \AA}{ }^{*}$ of the Na-mica free samples. Our choice of the locking position of the MNKM spacing is explained in Appendix A, and further reasons for these choices will be given in another paper (Kisch, in preparation).

The deconvolutions were thus carried out on the EG-solvated traces using the following procedures:

(1) Correction of all peak positions for ${ }^{\circ} 2 \theta$ shifts in the XRD trace using the shift in the measured ${ }^{\circ} 2 \theta$ position of the quartz peak at $20.86^{\circ} 2 \theta$.

(2) Fitting FWHM of the 5- $\AA$ peak of WKM with three mica peaks (plus the chlorite peak at ca. $18.8^{\circ} 2 \theta$ ): locked peak positions at $18.40^{\circ} 2 \theta$ (paragonite) and $18.00^{\circ} 2 \theta$ (Na-K mica), and the WKM peak locked or unlocked at its visual peak position (generally $\left.17.75-17.78^{\circ} 2 \theta\right)$. 
(3) Fitting FWHM of the 10- $\AA$ peak of WKM with three peaks (ignoring the I/S tail, if present): locked peak positions at $9.17^{\circ} 2 \theta$ (paragonite) and 9.00-9.01 $2 \theta$ (MNKM), and the WKM peak locked at its position as calculated from (2), usually $8.85-8.86^{\circ} 2 \theta$, or unlocked at the visual peak position. Since the WKM peak in most samples is much stronger than the MNKM peak - as evident from their relative intensities in the $17.74-18.40^{\circ} 2 \theta$ range - , leaving the selected WKM peak position unlocked has little effect on its final position and fitted FWHM, except for very few samples exceptionally rich in MNKM (see Appendix A).

Fits with MNKM peaks with very long high-angle tails and symmetric paragonite peaks to be disregarded. In very Na-mica rich samples with a discrete peak of regular MNKM in the 18.04-18.18 $2 \theta$ range, either locking an additional peak at ca. 9.02-9.03 $2 \theta$ - corresponding to this regular MNKM - ("4-layer fits") or leaving the paragonite peak unlocked, helps to reduce scatter, and give very similar results.

\section{Chlorite 'crystallinity'}

Attempts to use chlorite 'crystallinity' to establish a gradient of metamorphic grades were not successful. The 002 chlorite peak at approximately $7.08-7.12 \AA\left(12.5-12.43^{\circ} 2 \theta\right)$ is broadened by the presence of an unresolved kaolinite peak at approximately $7.13 \AA$ $\left(12.40^{\circ} 2 \theta\right)$ in some of the traces, single-peak fits of the 7 - $\AA$ peak giving FWHM values from $0.19^{\circ}$ to $0.24^{\circ} \Delta 2 \theta$, with some values of up to $0.31^{\circ} \Delta 2 \theta$ in some kaolinite-rich samples with strongly asymmetric 7.1- $\AA$ reflections with low-angle tails. Two peak deconvolutions with a kaolinite peak locked at $12.33^{\circ} \Delta 2 \theta$ or with an unlocked kaolinite peak, which migrates to $12.33-12.45^{\circ} \Delta 2 \theta$, mostly generate smaller $\mathrm{FWHM}_{7.1 \AA}{ }^{*}$ values in a narrow range of $0.17-0.205^{\circ} \Delta 2 \theta$, with a few values up to $0.25^{\circ} \Delta 2 \theta$. The predominant chlorite $\mathrm{FWHM}_{7.1 \AA}{ }^{*}$ values are lower than both the ca. $0.25^{\circ} \Delta 2 \theta$ equivalent at the scan rates of $0.5^{\circ} / \mathrm{min}$ used here of the epizone-anchizone boundary for chlorite 'crystallinity' of $0.292^{\circ} \Delta 2 \theta$ of Árkai (1991, Fig. 4d) for faster scan rates of $2^{\circ} / \mathrm{min}$ on EG-solvated preparations (cf. Kisch, 1990), and the similar $0.242^{\circ} \Delta 2 \theta$ limit of Árkai et al. (1995, Fig. 2b) for scan rates of $0.5^{\circ} / \mathrm{min}$ on air-dried preparations, and thus indicate low-'epizonal' grades of metamorphism. However, they fail to show a discernable correlation with the grade of metamorphism from the WKM FWHM values.

\section{Results}

Virtually all samples contain WKM, quartz and chlorite. Na-mica was detected in well over half of the samples studied. Its identification is facilitated by the common absence of albite from the investigated $<2 \mu \mathrm{m}$ and $2-6 \mu \mathrm{m}$ size fractions, notably of samples containing Na-rich micas, and also from the untreated samples (in the few cases were these have been studied). The ratio of $\mathrm{Na}$ mica to WKM - as expressed by the intensity ratios $I_{4.89-4.90 \AA} / I_{5 \AA}$ and $I_{4.82 \AA} / I_{5 \AA}$ and the height of the MNKM plateau at $27.2-27.6^{\circ} 2 \theta$ $\mathrm{K} \alpha(3.28-3.23 \AA)-$ is somewhat lower in the $2-6 \mu \mathrm{m}$ than in the $<2 \mu \mathrm{m}$ size fractions of virtually all samples, but a discrete peak at $27.35-27.45^{\circ} 2 \theta \mathrm{K} \alpha(3.25-3.26 \AA)$, indicative of a regular $\mathrm{Na}-\mathrm{K}$ mixed-layer mica with ca. $60 / 40 \mathrm{Na} / \mathrm{K}$, is commonly more distinct. The low Na-mica/WKM ratio in the coarser size fractions is considered as an indication that the Na-mica is largely authigenic. In contrast, the chlorite/WKM ratio varies from similar to notably higher in the $2-6 \mu \mathrm{m}$ than in the $<2 \mu \mathrm{m}$ size fraction, indicating that the chlorite is largely clastic. Albite was not detected except in a few samples from the Five Mile Creek and Twenty Mile Creek profiles in the southernmost area of the MC block, including two containing probable phlogopite, and in one sample from the Glen Herring Shale.

The FWHM values of the unfitted $10-\AA$ peaks as measured on strip charts of slides of the air-dried $<2 \mu \mathrm{m}$ size fraction are listed in Table 1 and plotted on the map (Fig. 4). The broader peaks show a marked asymmetry with high-angle tails or shoulders, indicating the presence of reflections in the range $9.0-9.2^{\circ} 2 \theta(9.8-9.6 \AA)$, unresolved or partly resolved from the $10-\AA$ $W K M$ peak at $8.84-8.86^{\circ} 2 \theta$, indicative of the presence of paragonite and/or MNKMs in addition to that of WKM.

Four categories of the value of the relative intensity of the $\mathrm{Na} / \mathrm{K}$ mica "plateau", $I_{\text {plateau } 4.89-4.90 \AA} / I_{5 \AA}$, used as an approximate indication of the Na-mica content, are indicated on the symbols on map (Fig. 4) by fillings in different shades of fill. The highest relative intensities of $>0.50$ (black fill) are restricted to samples with the broadest unfitted $10-\AA ̊$ peaks (FWHM $\geq 0.40^{\circ} \Delta 2 \theta$ ); high intermediate relative intensities of $0.30-0.50$ (dark-grey fill) to those with intermediate and broad 10 - $\AA$ peaks (FWHM $\geq 0.30^{\circ} \Delta 2 \theta$ ), low intermediate relative intensities of $0.20-0.30$ (light-grey fill) occur mainly in those with 10 - $\AA$ peaks with FWHM $0.25-0.40^{\circ} \Delta 2 \theta$, while virtually all samples with narrow unfitted $10-\AA$ peaks $\left(\mathrm{FWHM}<0.20^{\circ} \Delta 2 \theta\right)$ and most with FWHM $0.20-0.30^{\circ} \Delta 2 \theta$ show low relative intensities of $<0.25$ (white fill). The FWHM values of the unfitted $10-\AA$ peaks thus reflect the effect of peak broadening due to content of paragonite and/or MNKMs in addition to that of the WKM 'crystallinity'; consequently, they cannot be used as parameters of the latter, and thus of the degree of very-low-grade metamorphism. The different fill shades show the concentration of the Na-mica bearing samples (black and dark-grey fill) in the central part of the MC Formation and their virtual absence from the southeastern "Dromedary" area and the northern basin margin. Moreover, note the uncommon combination of low relative intensities $(\leq 0.07)$ with intermediate 10 - $\AA$ peak widths of $0.27-0.31^{\circ} \Delta 2 \theta$ in most samples from the Glen Herring Shale.

The $\mathrm{FWHM}_{10 \AA}{ }^{*}$ values of the fitted WKM 10- $\AA$ reflections are listed in Table 1, and five categories of these widths are plotted in Fig. 5. A distinct zoning is seen, particularly in the Nullagine River profile.

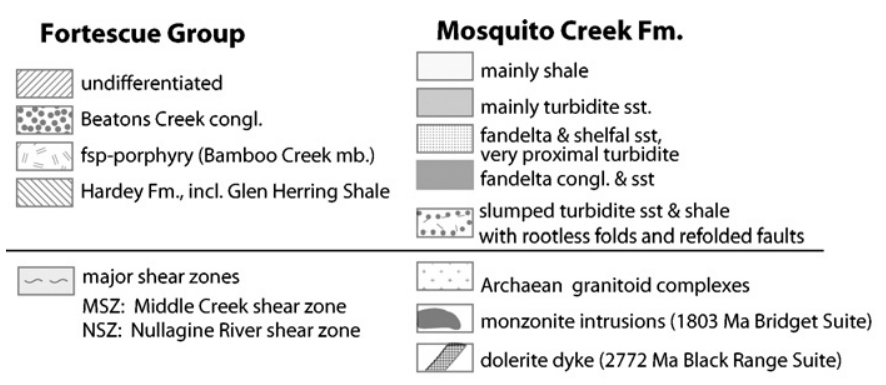

Geological legend to Figs. 4-6.

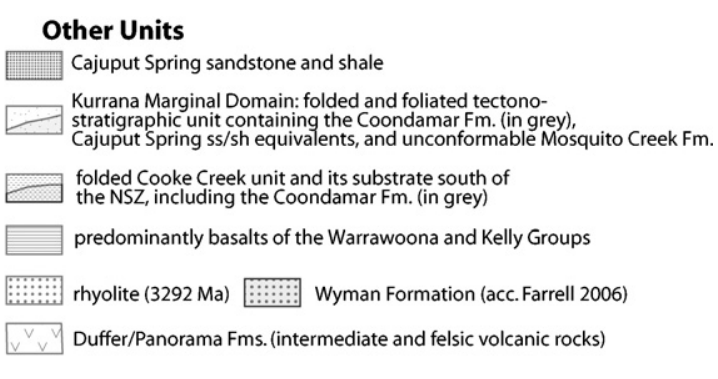




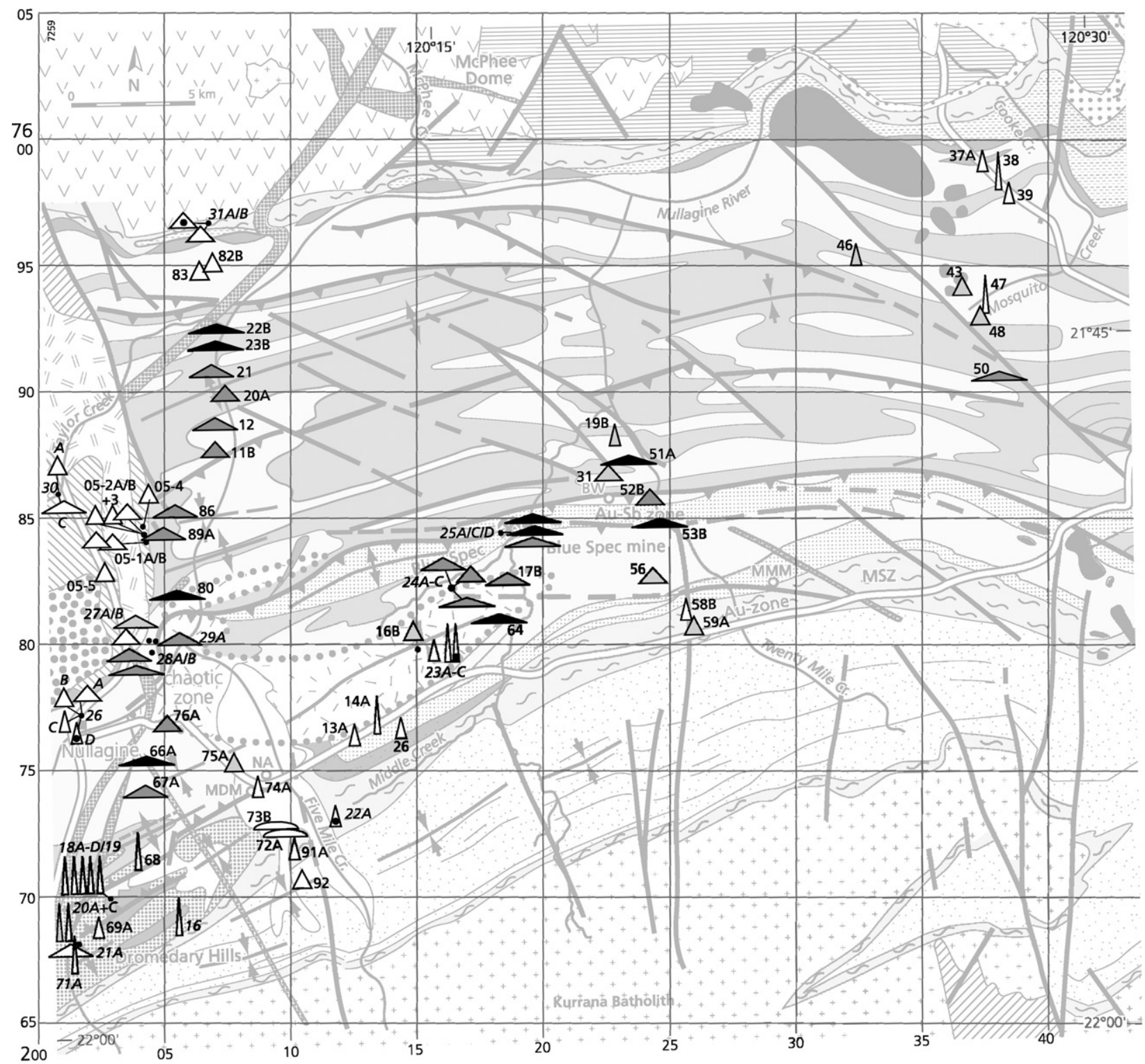

FWHM of unfitted $10-\AA ̊$ peak as measured on strip charts $(\Delta 2 \Theta)$

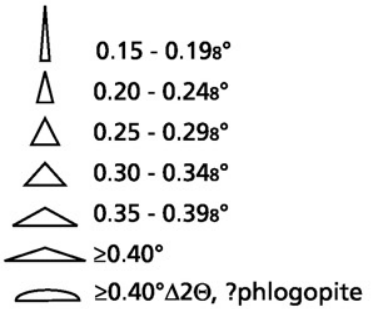

Filling of symbols indicates approximate content of Na-mica as indicated by four classes of the value of $\mathrm{I}_{\text {Na-K-mica }} 4.90 \mathrm{~A}$ Ak-mica $5 \mathrm{~A}$, the ratio of the intensity of the Na-K mica 'plateau' at $4.90 \AA\left(18.10^{\circ} 2 \Theta\right)$ to that of the K mica peak at $5 \AA\left(\approx 17.74^{\circ} 2 \Theta\right)$ :

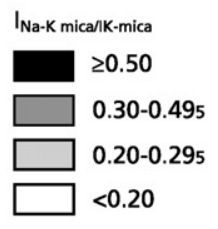

- $\mathrm{FWHM} \geq 0.20^{\circ} \Delta 2 \Theta$ without data on $\mathrm{I}_{\mathrm{Na}-\mathrm{K} \text { mica/K-mica }}$ (3 samples)

73в Sample numbers

(sample numbers with 00 prefix in italics)

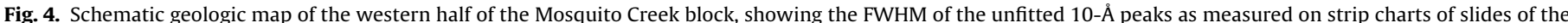

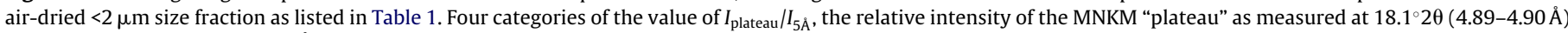

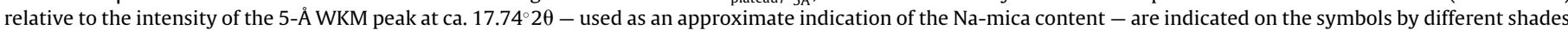
of grey.

Broad and broad-intermediate values of $0.23-0.32^{\circ} \Delta 2 \theta$ characteristic of middle and high-grade anchimetamorphism are concentrated in the central part of the MC Formation and the overlying Glen Herring Shale (symbols of which are marked by black dots within the symbols) up to $9 \mathrm{~km} \mathrm{~N}$ and NNE of Nullagine (77-86 $\mathrm{N})$ and its ENE continuation to the Blue Spec mine, whereas the samples from the Dromedary area and the southern part of the Middle Creek profile show narrow FWHM values of $<0.20^{\circ} \Delta 2 \theta$ (with only one exception), indicating "epimetamorphic" grade; probable phlogopite in two samples along Middle Creek indicates that biotite grades were attained locally. Narrow-intermediate values of $0.20-0.24^{\circ} \Delta 2 \theta$ predominate in the intervening area between Nullagine and Nullagine Airport between 74 and 76 $\mathrm{N}$ and along the Five Mile Creek profile (one exception, with $0.25^{\circ} \Delta 2 \theta$ ), and in the $\mathrm{N}$ part of the Nullagine profile between 87 and $95 \mathrm{~N}$, with some broader peaks of $0.26-0.27^{\circ} \Delta 2 \theta$ recur- 


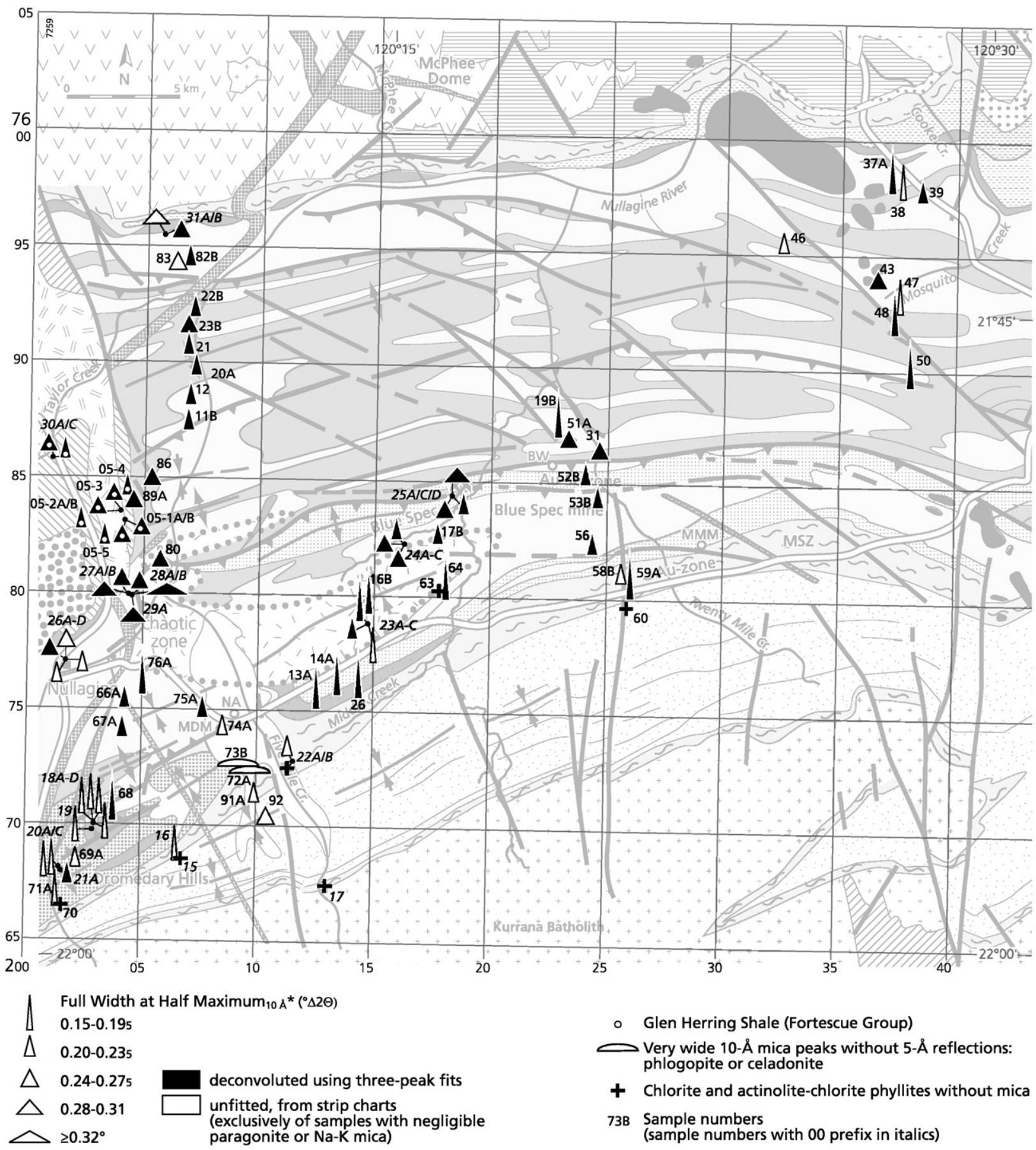

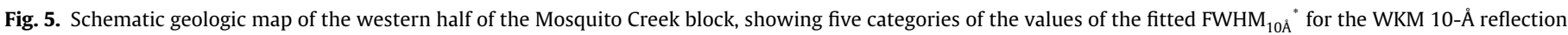
from Table 1.

ring in the northernmost part of the profile, between 94 and 96 N.

The 15 samples from the Middle Creek profile show a distinct contrast between intermediate values of $0.21-0.29^{\circ} \Delta 2 \theta$ in the anticlinal area around Blue Spec Mine, and narrow values of $0.15-0.20^{\circ} \Delta 2 \theta$ further $S$ and SE. The 8 samples from the Twenty Mile Creek profile show uniformly narrow-intermediate values of $0.20-0.23^{\circ} \Delta 2 \theta$ in the central and southern section and some broader values of $0.26^{\circ} \Delta 2 \theta$ and one anomalous narrow value of $0.17^{\circ} \Delta 2 \theta$ in the northern section, WNW of the Blue Spec Mine. In the 8 samples from the Mosquito Creek area, to the WNW of the area, the values are narrower again, $\leq 0.22^{\circ} \Delta 2 \theta$ (one exception, with $0.25^{\circ} \Delta 2 \theta$ ).
On the plot of $\mathrm{FWHM}_{5 \AA}{ }^{*}$ of the fitted WKM 5- $\AA$ reflections (Table 1 and Fig. 6), this zoning is even more distinct: broad and broad-intermediate values of $0.25-0.32^{\circ} \Delta 2 \theta$ cluster in the central part of the MC Formation and the overlying Glen Herring Shale up to $9 \mathrm{~km} \mathrm{~N}$ and NNE of Nullagine between 79 and $86 \mathrm{~N}$ and its ENE extension to the Blue Spec mine at 84-85 N, in the northern part of the Nullagine River profile $\mathrm{N}$ of $90 \mathrm{~N}$, and in the Twenty Mile Creek profile $\mathrm{N}$ of $84 \mathrm{~N}$. These are fringed to the $\mathrm{S}$ by zones of moderately narrow-intermediate $\mathrm{FWHM}_{5 \AA}{ }^{*}$ values of $0.21-0.23^{\circ} \Delta 2 \theta$ : in the area between Nullagine and Nullagine Airport between 74-77 $\mathrm{N}$ (4 samples) and in the Twenty Mile Creek profile S of $83 \mathrm{~N}$ (2 sample), while similar values recur in the intermediate-north part of the Nullagine profile between 87 and $90 \mathrm{~N}$. In the Dromedary 


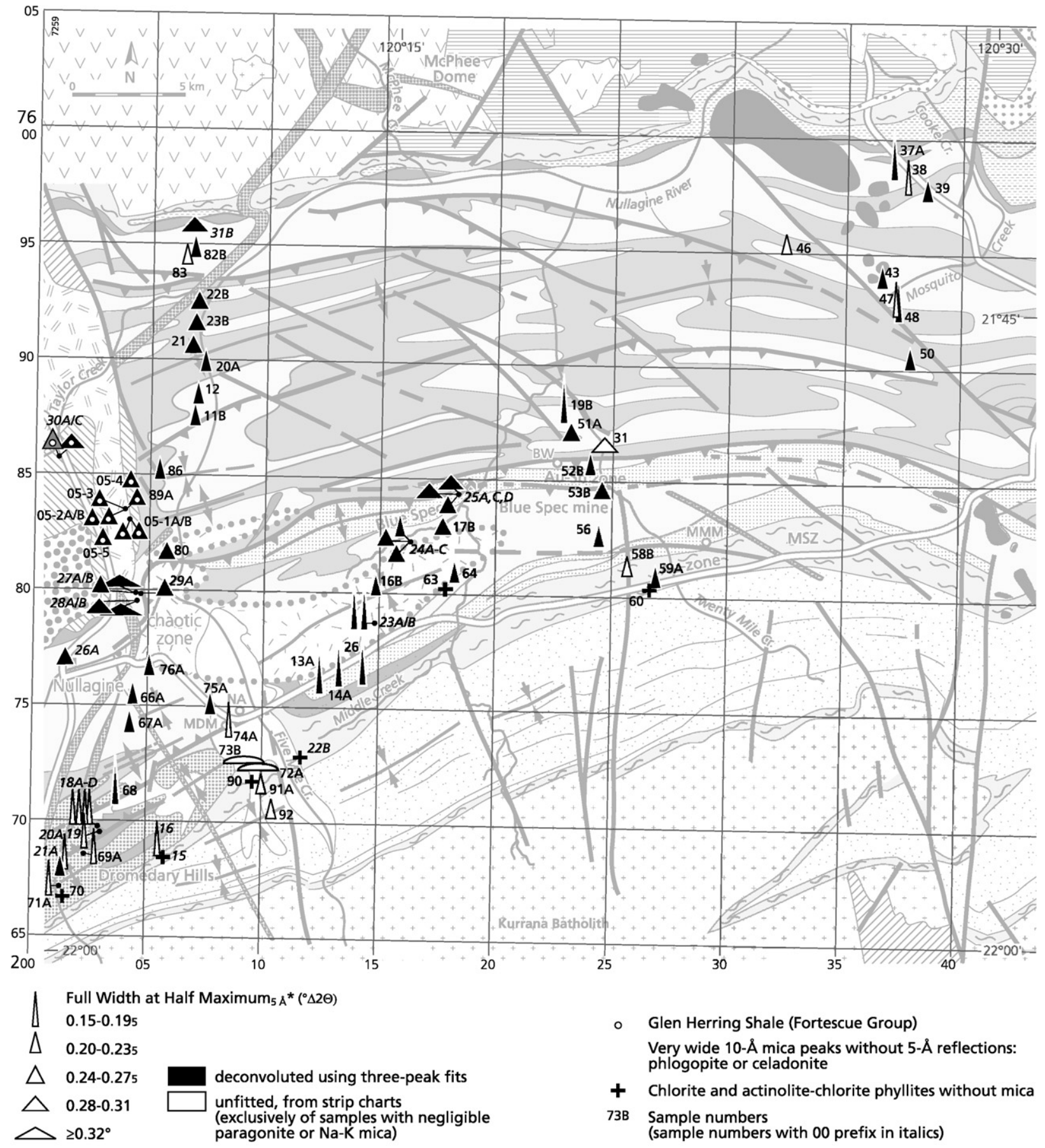

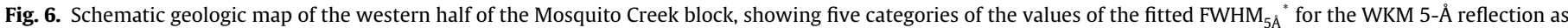
listed from Table 1.

area to the $S$, the southern part of the Middle Creek profile, and the Mosquito Creek area to the WNW of the area, the $\mathrm{FWHM}_{5 \AA}{ }^{*}$ values are exclusively $0.18-0.22^{\circ} \Delta 2 \theta$.

It is therefore possible to distinguish a broad zoning in the grade of metamorphism of the MC Block from (a) mid- to high-grade anchimetamorphic grades in the central and parts of the western section - from Nullagine $10 \mathrm{~km}$ to the north and its ENE continuation to the Blue Spec mine - to (b) slightly higher grades in the fringing areas to the $\mathrm{N}$ and the $\mathrm{S}$, and in most of the Twenty Mile Creek profile, with (c) the highest, "epimetamorphic" grades in the Mosquito Creek area to the east, and particularly the Dromedary area to the south.
The lower grade in the zone from Nullagine to the Blue Spec Mining Centre is shown by the presence of several samples with broad $\mathrm{FWHM}_{10 \AA}{ }^{*}$ of $0.25-0.30^{\circ} \Delta 2 \theta$, and two with $0.31-0.32^{\circ} \Delta 2 \theta$, all of which are entirely lacking from the zone adjoining to the $\mathrm{S}$. This effect is even more marked for $\mathrm{FWHM}_{5 \AA}{ }^{*}$, all except one sample from this zone showing $0.24-0.29^{\circ} \Delta 2 \theta$, and two $0.32-033^{\circ} \Delta 2 \theta$, whereas all values to the $S$ are $\leq 0.215^{\circ} \Delta 2 \theta$.

The FWHM values obtained with three-peak fitting show no distinct break in the grade of metamorphism between the central part of MC Formation in the Nullagine River profile and the Glen Herring Shale immediately overlying it to the west. However, the very low intensity ratios $I_{4.89-4.90 \AA} / I_{5 \AA}$ of $\leq 0.07$, and the presence of a 
low-angle rather than a high-angle tail to the 10 - $\AA$ peak in traces of samples from the Glen Herring Shale indicate the virtual absence of Na-mica, suggesting that the broad unfitted $10-\AA$ peak widths of $0.26-0.31^{\circ} \Delta 2 \theta$ might reflect factors other than presence of $\mathrm{Na}-$ mica, such as poor illite 'crystallinity'. Application of the three-peak deconvolution procedure to these traces, for the sake of uniformity, generates $\mathrm{FWHM}_{10 \AA}{ }^{*}$ values of $0.21-0.26^{\circ} \Delta 2 \theta$, narrower by some $0.04-0.08^{\circ} \Delta 2 \theta$. Insofar as the higher grade of metamorphism from these narrower $\mathrm{FWHM}_{10 \AA}{ }^{*}$ values may be a mere artifact of the deconvolution, in masking poor illite 'crystallinity' due to factors other than presence of Na-mica, deconvolution of these peaks may not be justified. If unfitted peaks were to be used for the Glen Herring Shale samples, the break in grade of metamorphism with the central part of the MC formation would be wider by some $0.04-0.08^{\circ} \Delta 2 \theta$. Further deconvolution of the broad $10-$ $\AA$ and 5 - $\AA$ peaks in most of these traces (cf. Brime et al., 2002) yields strong peaks with $\mathrm{FWHM}_{\mathrm{WCI}}{ }^{*} 0.17-0.22^{\circ} \Delta 2 \theta$ and weaker peaks with $\mathrm{FWHM}^{*}>0.4^{\circ} \Delta 2 \theta$ - the latter mostly with a $2 \theta$ spacing somewhat higher than the 10- $\AA$ and somewhat lower than the 5 -Å WPI peak -, possibly representing superposition a of a poorly'crystalline' I/S \pm CPI peak upon persisting clastic WPI K-mica. The possible effect of the applied deconvolution procedure on the composite $10-\AA ̊$ reflection of intermediate and poor WKM 'crystallinity' requires further study.

The mean $b_{0}$ of WKMs of low-grade pelitic schists is a measure of the metamorphic $\mathrm{P} / \mathrm{T}$ gradient ranging from $8.994 \AA$ in the lowP/T Bosost (Pyrenees) area (Sassi and Scolari, 1974; 8.986 Å in "truly pelitic rocks", Guidotti and Sassi, 1986, p. 368 and Table 2) - in the higher grade schists of which abundant andalusite and cordierite occur - and $8.992 \AA$ in the Buchan area (Fettes et al., 1976; see also Guidotti and Sassi, 1986, p. 368 and Table 2), through 9.038 Å for the Barrovian-type metamorphism in the Permo-Mesozoic cover of the Eastern Alps (Sassi and Scolari, 1974), to $9.042 \AA$ An high-P/T areas (Kisch et al., 2006, Table 1 ). The $b_{0}$ of 41 untreated samples from the Mosquito Creek area are shown on the cumulative frequency plot (Fig. 7).

The mean of the untreated samples is $8.979 \AA$, somewhat lower than the $8.986 \AA$ for the low-P/T samples of "truly pelitic rocks" from Bosost (Guidotti and Sassi, 1986, p. 368 and Table 2), and therefore indicate an even lower metamorphic $\mathrm{P} / \mathrm{T}$ gradient. However, Guidotti and Sassi $(1976,1986)$ found that micas associated with paragonite (their "W" and "X" assemblages) have lower $b_{0}$ values than those associated with albite without paragonite ("Y" assemblages), without specifically mentioning MPG, and that determination of the $\mathrm{P} / \mathrm{T}$ gradient should be based on assemblages without paragonite, but without specifically referring to MNKMs. Since distinct albite was detected in only 5 of these 41 samples, all without Na-mica, they are not plotted separately, but two of these show $b_{0}$ values of $9.01-9.02^{\circ}$, the highest found. As a "proxy", the 25 samples with a low Na-mica content $\left(I_{\text {plateau }} / I_{5 \AA}\right.$ ratio $\left.\leq 0.30\right)$ and the 16 samples with a high Na-mica content $\left(I_{\text {plateau }} / I_{5 \AA}\right.$ ratio $\left.>0.30\right)$ are plotted separately; the former population shows a somewhat higher mean $b_{0}$ value $(8.985 \AA)$ than the latter $(8.973 \AA)$ - in part reflecting the inclusion of the five Na-mica poor albite-bearing samples, with a mean $b_{0}$ of $8.993 \AA$ - but the small gap of $0.012 \AA$ between the mean $b_{0}$ values of the two populations is in accordance with its narrowing at low-P conditions (Bossière et al., 1979; see also Kisch et al., 2006, p. 124). The mean $b_{0}$ of the five samples with distinct albite alone, $8.993 \AA$, would be indicative of a somewhat higher, but still "low-pressure" $\mathrm{P} / \mathrm{T}$ "Buchan" gradient of metamorphism. The $b_{0}$ values of the six samples from the Glen Herring Shale in the Na-mica-poor population are indistinguishable from those of the MC Formation, suggesting that they were metamorphosed under a very similar $\mathrm{P} / \mathrm{T}$ regime.

$b_{0}$ was also measured on the $<2 \mu \mathrm{m}$ and the $2-6 \mu \mathrm{m}$ size fractions of 28 additional samples (Fig. 7), 19 with $I_{\text {plateau }} / I_{5 \AA}$
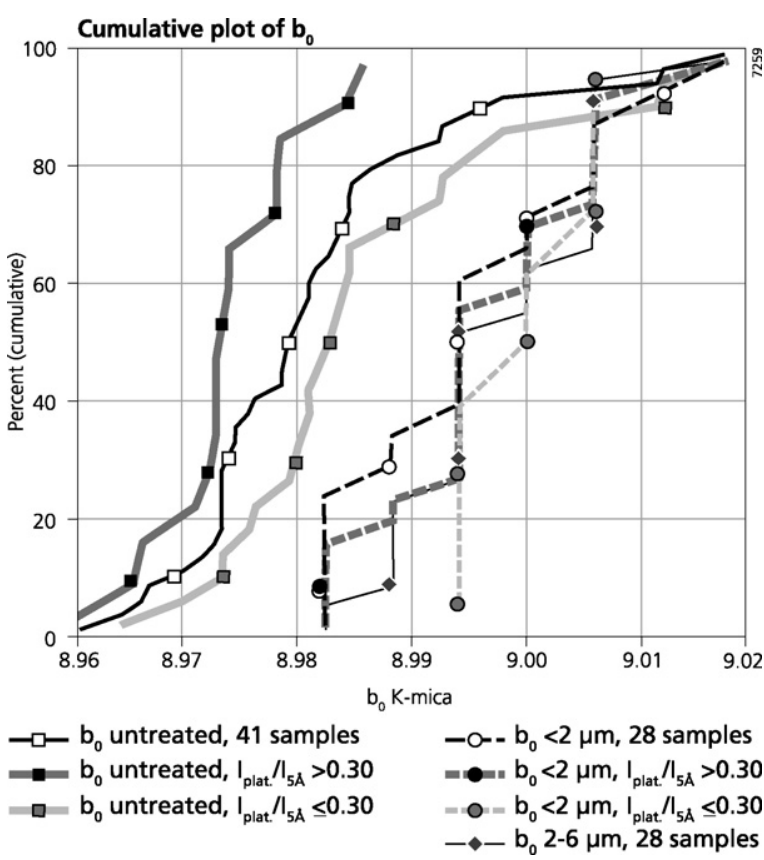

Fig. 7. Cumulative frequency plot of the $b_{0}$ lattice parameter of WKMs from 45 untreated samples from the Mosquito Creek area; the mean of the untreated samples is $8.979 \AA$. The $b_{0}$ of the WKMs from the samples with a high Na-mica content $\left(I_{\text {plateau }} / I_{5 \AA}\right.$ ratio $\left.>0.30\right)$ and with a low Na-mica content $\left(I_{\text {plateau }} / I_{5 \AA}\right.$ ratio $\left.\leq 0.30\right)$ are also plotted separately; the former show a slightly lower mean $b_{0}$ value ( $8.973 \AA$ ) than the latter $\left(8.985 \AA\right.$ ). Also shown is the cumulative curve for $b_{0}$ measured on the $<2 \mu \mathrm{m}$ and the $2-6 \mu \mathrm{m}$ size fractions of 28 additional samples; the mean $b_{0}$ equals 8.994 Å for both size fractions.

ratio $\leq 0.30$, and 9 with $I_{\text {plateau }} / I_{5 \AA}$ ratio $>0.30$. Distinct albite was found in only two of the Na-mica poor samples (not plotted separately), which show high $b_{0}$ values of 9.01-9.02 $\AA$ in the $<2 \mu \mathrm{m}$ and/or 2-6 $\mu \mathrm{m}$ size fractions. The mean $b_{0}, 8.994 \AA$ for both size fractions, is higher by $0.015 \AA$ than for the untreated samples and equals the mean value for Bosost. This might indicate either (a) that these small grain-size fractions, which presumably represent the most "authigenic" K-micas, were formed under slightly higher, but still very low $\mathrm{P} / \mathrm{T}$ gradients, or (b) that the lower $b_{0}$ of the untreated samples reflects the presence of detrital micas of igneous origin. However, if this were the case, the more "detrital" $2-6 \mu \mathrm{m}$ fraction would be expected also to show a higher mean $b_{0}$ than the more "authigenic" $<2 \mu \mathrm{m}$ fraction; the identical mean $b_{0}$ for these two size fractions appears to exclude the second option.

$d_{002}$ in the $<2 \mu \mathrm{m}$ fractions of all samples from the MC Formation - including those very rich in Na-mica - is between 9.994 and $9.972 \AA$, mostly between 9.98 and $9.99 \AA \AA$; it is slightly higher, between 9.988 and $10.01 \AA$, in the samples from the Glen Herring Shale. The combination of $d_{002}$ around $9.985 \AA$ and a mean $b_{0}$ of $8.994 \AA$ in the $<2 \mu \mathrm{m}$ size fractions indicates that the WKM is poor in $\mathrm{Na}$, with $\mathrm{Na}^{*}[=100 \mathrm{Na} /(\mathrm{Na}+\mathrm{K})] \mathrm{ca} .11$, and an $\mathrm{Fm}\left[=\mathrm{Fe}_{\mathrm{T}}+\mathrm{Mg}+\mathrm{Mn}\right]$ of ca. 0.1 (Guidotti et al., 1992, Fig. 5). Coexistence of such Na-poor WKMs with paragonite indicates very low temperatures of formation of the WKM-paragonite assemblage (cf. Guidotti and Sassi, 1976, Fig. 6).

Prismatic porphyroblasts of probable chloritoid, common in slates from the Mosquito Creek area in the contact aureole of the quartz syenite to quartz monzonite body of the Paleoproterozoic Bridget Suite (Bagas, 2005, p. 25), dated at $1803 \pm 19 \mathrm{Ma}$ (Nelson, 2002), are strongly retrograded by subsequent hydrothermal action.

Some of the traces contain appreciable amounts of kaolinite and/or smectite, in some cases to the exclusion of chlorite. These samples appear to be concentrated in the Mount Daniel Mine 
area of the Five Mile Creek profile between coordinates 7574 and 7570 (where virtually all samples contain kaolinite \pm smectite), the southernmost stretch of the Nullagine River profile, $S$ of coordinate 7569 (smectite; no kaolinite), and SW of Golden Spec/Blue Spec Mining Centre between coordinates 7577 and 7576 (kaolinite) in a WSW-ENE strip in or within $2.5 \mathrm{~km}$ of the Middle Creek shear zone. They also occur in the northernmost stretch of the Nullagine River profile, $\mathrm{N}$ of Taylor Creek (coordinate 7593), and in the Mosquito Creek area. As both these minerals disappear during "diagenesis", and do not persist into the higher grades of anchimetamorphism, they must have formed subsequent to the regional metamorphism, presumably as a result of hydrothermal activity. In the Mosquito Creek area, such activity may be related to the retrogradation of the chloritoid porphyroblasts in the granite contact aureole.

\section{Discussion}

Unfortunately, there is a lithological difference between the lower-grade central area and the higher-grade Dromedary area, in that samples with high contents of paragonite and $\mathrm{Na}-\mathrm{K}$ mixed-layer micas predominate in the former and are virtually absent from the latter. Peak fitting has a narrowing effect on the FWHM values of these Na-mica-rich samples, whereas the largely Na-mica-free samples from the higher-grade Dromedary area have narrow peaks without fitting: peak fitting has a much stronger effect on the FWHM values of samples in the former than in the latter area. It might therefore be argued that the zoning described above merely reflects differences in the primary lithology between the areas, the broader fitted $\mathrm{FWHM}^{*}$ values in the samples of the "lower-grade" area being mere artefacts of an insufficiently vigorous peak fitting procedure on these samples, i.e. that with a more vigorous peak-fitting procedure the fitted $\mathrm{FWHM}^{*}$ values in the "lower-grade" central area would be as narrow as in the "highergrade" Dromedary area.

However, several lines of argument militate against such views:

(a) The unfitted FWHM values of the WKMs in the few Na-micapoor samples in the "lower-grade" area (02-26B, C, D; 00-31A; 02-83) are similar to the fitted $\mathrm{FWHM}^{*}$ values in Na-mica-rich samples from the same and nearby locations, suggesting that the adopted peak fitting procedure yields $\mathrm{FWHM}^{*}$ values representing the WKM "crystallinity".

(b) More "vigorous" fitting procedures, i.e. choosing the position of the MNKM peak closer to the WKM peak at $8.85-8.87^{\circ} 2 \theta$, i.e. at a $2 \theta$ angle lower than $9.00-9.01^{\circ} 2 \theta$ currently used, yield narrowed $\mathrm{FWHM}_{10 \AA}{ }^{*}$ values, but such procedures will narrow all WKM peaks, including those of the samples with little or no Na-mica in the "high-grade" area, so that the differences noted above are maintained, although at narrower $\mathrm{FWHM}_{10 \AA}{ }^{*}$ values. Narrowing the $\mathrm{FWHM}_{10 \AA}{ }^{*}$ of some of the low-grade samples such as $00-28 \mathrm{~B}$ and $00-25 \mathrm{C}$ to values similar to those of some of the "high-grade" samples such as 00-21A, can only be achieved by choosing the position of the MNKM peak at $2 \theta$ angles even closer to the WKM peak at $8.85-8.87^{\circ} 2 \theta$, e.g. $8.90^{\circ} 2 \theta$, but the FWHM $_{10 \AA}{ }^{*}$ values of $0.15-0.17^{\circ} 2 \theta$ thus obtained are unrealistically narrow and are achieved at the cost of narrowing the $\mathrm{FWHM}_{10 \AA}{ }^{*}$ of all the samples to absurdly narrow values of $0.13-0.21^{\circ} 2 \theta$.

We conclude, therefore, that the fitting procedures adopted generate $\mathrm{FWHM}_{10 \AA}{ }^{*}$ values from the Na-mica rich samples that are in reasonable agreement with those of the Na-mica free samples, and express the degree of metamorphism.

The zone of somewhat lower grades extending from Nullagine to the Blue Spec Mine area corresponds to an anticline just south of the Blue Spec thrust. This lower grade reflects less deep burial, and could be explained by assuming that this anticline corresponds to the crest of a growth fold with thinner sedimentary cover (cf. Nijman et al., submitted for publication), the rocks of which therefore would have been less deeply buried than those the adjoining synclinal areas.

The width of the gap in metamorphic grade between the Mosquito Creek sequence and the overlying Glen Herring Shale is of importance, in view of some doubts about the precise stratigraphical position of the shale NNE of Nullagine because of the complexity of the unconformities in that area (cf. Blake, 1993): the shale may be intermediate between the MC Formation proper and the Fortescue Group. The deconvolution procedure affects the width of this gap in metamorphic grade, in that it narrows the $\mathrm{FWHM}_{10 \AA}{ }^{*}$ of the peaks of the latter samples to $0.22-0.27^{\circ} \Delta 2 \theta$, and $\mathrm{FWHM}_{5 \AA}{ }^{*}$ to $0.24-0.28^{\circ} \Delta 2 \theta$. Although traces of these show neither a paragonite peak at $4.82 \AA$ nor a MNKM plateau at $\approx 4.90 \AA$, and their peak broadening therefore must be due to other causes, for instance a broad Kübler index of the illite itself, we have nevertheless opted to apply the deconvolution procedure to these samples as well, for the sake of uniformity. The resulting absence of a distinct gap in the grade between the grades of metamorphism between the Mosquito Creek sequence and the overlying Glen Herring Shale would imply that the Mosquito Creek sequence was essentially metamorphosed after and together with the basal part of the Fortescue Group.

Alternatively, it may be argued that application of the deconvolution procedure to such Na-mica-free samples is inappropriate. If no deconvolution were to be applied to these samples, their $\mathrm{FWHM}_{10 \AA}$ and $\mathrm{FWHM}_{5 \AA}$ both would be appreciably broader, $0.27-0.32^{\circ} \Delta 2 \theta$, thus broadening the apparent metamorphic gap between them and the underlying Na-mica bearing Mosquito Creek samples.

In this case, there exists a slight but distinct gap in grade of metamorphism, which implies that the Mosquito Creek sequence was metamorphosed prior to the deposition of the Glen Herring Shale, which was subsequently metamorphosed to a grade only marginally lower than that of the upper part of the Mosquito Creek sequence.

\subsection{Composition of the Na-mica-bearing sediments}

Since paragonite is much poorer in $\mathrm{Na}$ and $\mathrm{Si}$ than albite (on an Al basis) $\mathrm{Na}_{2} \mathrm{Al}_{4}\left[\mathrm{Si}_{6} \mathrm{Al}_{2} \mathrm{O}_{20}\right](\mathrm{OH})_{4}=6 \mathrm{NaAlSi}_{3} \mathrm{O}_{8}-$ $2 \mathrm{Na}_{2} \mathrm{O}-12 \mathrm{SiO}_{2}+2 \mathrm{H}_{2} \mathrm{O}$, the presence of $\mathrm{Na}$-mica indicates a high alumina and/or low sodium content compared to pelitic rocks with albite. Since paragonite + quartz is chemically equivalent to albite + kaolinite or albite + smectite:

$$
\begin{aligned}
& \mathrm{Al}_{4}\left[\mathrm{Si}_{4} \mathrm{O}_{10}\right](\mathrm{OH})_{8}+2 \mathrm{NaAlSi}_{3} \mathrm{O}_{8} \\
& =\mathrm{Na}_{2} \mathrm{Al}_{4}\left[\mathrm{Si}_{6} \mathrm{Al}_{2} \mathrm{O}_{20}\right](\mathrm{OH})_{4}+4 \mathrm{SiO}_{2}+2 \mathrm{H}_{2} \mathrm{O} \text {, } \\
& \text { paragonite } \\
& \begin{array}{c}
\mathrm{Na}_{0.7} \mathrm{Al}_{4}\left[\mathrm{Si}_{7.3} \mathrm{Al}_{\text {b.7. }} \mathrm{O}_{20}\right](\mathrm{OH})_{4} \cdot n \mathrm{H}_{2} \mathrm{O}+1.3 \mathrm{NaAlSi}_{3} \mathrm{O}_{8} \\
=\underset{\substack{\text { beidellite } \\
\text { paragonite }}}{\mathrm{Na}_{2} \mathrm{Al}_{4}\left[\mathrm{Si}_{6} \mathrm{Al}_{2} \mathrm{O}_{20}\right](\mathrm{OH})_{4}}+5.3 \mathrm{SiO}_{2}+n \mathrm{H}_{2} \mathrm{O}
\end{array}
\end{aligned}
$$

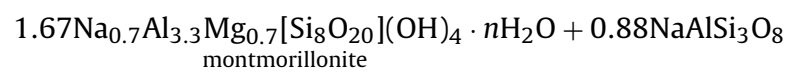

$$
\begin{aligned}
& =\mathrm{Na}_{2} \mathrm{Al}_{4}\left[\mathrm{Si}_{6} \mathrm{Al}_{2} \mathrm{O}_{20}\right](\mathrm{OH})_{4}+0.1 \mathrm{Mg}_{10} \mathrm{Al}_{2}\left[\mathrm{Si}_{6} \mathrm{Al}_{2} \mathrm{O}_{20}\right](\mathrm{OH})_{16} \\
& \text { paragonite clinochlore } \\
& +7 \mathrm{SiO}_{2}+(8-n) \mathrm{H}_{2} \mathrm{O}
\end{aligned}
$$

the protolith of the Na-mica bearing metasediments must have been kaolinite- and/or smectite-rich. The granitic-tonalitic compo- 
sition of the probable source rocks favors a kaolinite-rich rather than a smectite-rich protolith, strongly Al-enriched or alkalidepleted with respect to the source rocks by potassium and silica leaching under non-alkaline conditions during weathering, or strong alteration in a low-pH environment analogous to that leading to kaolinite-coal-"tonsteins".

Upon burial diagenesis in the presence of unstable clastic Kminerals such as K-feldspar and biotite anchimetamorphism, the kaolinite and smectite in such aluminous protoliths give rise to WKM, but in the absence of such clastic K-minerals kaolinite persists into anchimetamorphism, being replaced by Na-mica in a Na-rich environment, and by pyrophyllite in an environment deficient in both $\mathrm{K}$ and $\mathrm{Na}$ (cf. $m_{\mathrm{NaCl}}-m_{\mathrm{KCl}}-m_{\mathrm{HCl}}$ phase diagram in Garrels and Christ, 1965, Figs. 10.9 and 10.10), and rich in Si. Anchimetamorphic paragonite and pyrophyllite are formed in some originally kaolinitic rocks associated with anthracitic coals. The Lower Liassic black shale formation in the Jura Mountains and below the Molasse Basin - the "unmetamorphic" equivalent of the anchimetamorphic Lower Liassic of the northern Glarus Alps in which paragonite/phengite mixed-layer and paragonite (Frey, 1970, Fig. 4; Frey, 1978, Fig. 5) are almost ubiquitous, often accompanied by pyrophyllite - contains illite-smectite mixed-layer as the main clay mineral, typically accompanied by kaolinite (Frey, 1970, Fig. 2; Frey, 1974, p. 496; Frey, 1978, Fig. 3). Frey assumes that the paragonite formed from irregular illite/montmorillonite mixed-layer through intermediate rectorite (regular mixed-layer paragonite/montmorillonite) and paragonite/muscovite mixedlayer(Frey, 1970, p. 271; Frey, 1974, p. 496), and favors replacement of the kaolinite by pyrophyllite. However, most samples of the underlying anchimetamorphic Quartenschiefer, equivalent of the redbeds of the Upper Middle Keuper (Upper Triassic) in which illite/montmorillonite mixed-layer is abundant, but from which kaolinite is absent (Frey, 1970, Fig. 2), do not contain paragonite or paragonite/phengite mixed-layer (Frey, 1970, Fig. 3). We therefore tentatively favor formation of anchimetamorphic Na-mica at least in part from a kaolinitic protolith.

Kubler (1968, pp. 390-391) already noted the effects of "a draconian deficit in potassium, an excess of sodium relative to potassium" on the development of micas during anchimetamorphism. Thus, the persistence of pyrophyllite in these and other anchimetamorphic pelites rocks merely reflects the deficiency in alkali, as evident from the absence of detrital feldspar from the anchimetamorphic Lower Liassic black shales (Frey, 1978, p. 106) and from the pyrophyllite-bearing metapelites of the PhylliteQuartzite Unit of from eastern Crete (Theye and Seidel, 1991, Table 1 ), in the presence of which it would be replaced by WKM and/or Na-mica.

Since kaolinite does not form in alkali-rich environments, the alkali-depletion leading to the formation of a kaolinite-rich protolith must have taken place in a low-pH environment, presumably as a result of tropical weathering, prior to the deposition of the MC Formation alteration. Moreover, the comparatively high paragonite content and the absence of albite from the coarser, presumably more detrital, 2-6 $\mu \mathrm{m}$ and whole-rock samples suggests that albite may already have been absent from the protolith sediment. If the Na-mica formed exclusively from a metamorphic reaction between kaolinite and albite, it is surprising that no excess reactant (in the case of kaolinite converted to pyrophyllite upon metamorphism) remains after exhaustion of the other reactant. It is probable, therefore, that the metamorphic Na-mica was formed in a possibly feldspar-poor sediment at the expense of an aluminous clastic phyllosilicate predecessor, presumably kaolinite, by reaction with a Na-rich, intermediate-pH solution at anchimetamorphic temperatures (cf. $m_{\mathrm{NaCl}}-m_{\mathrm{KCl}}-m_{\mathrm{HCl}}$ phase diagram in Garrels and Christ, 1965, Fig. 10.10). Another option is the direct partial replacement of clastic WKM by Na-mica in a feldspar-poor sediment by reac- tion with such a Na-rich solution, possibly seawater or Na-rich lake water, at anchimetamorphic temperatures. Such a replacement would imply a narrow range of both $m_{\mathrm{Na}^{+}}$and $m_{\mathrm{K}^{+}}$much lower than present-day seawater at intermediate-pH, i.e. fresh water, or the unlikely combination of low $\mathrm{pH}$ and high $\mathrm{m}_{\mathrm{Na}^{+}}$.

\section{Conclusions}

(1) Most of the metasediments from the turbidite sequences of the Mosquito Creek Formation contain Na-mica - discrete paragonite, random MNKMs and/or a regular 65-35 to 60-40 Na-K mixed-layer mica. These rocks do not contain albite. The metasediments of the Dromedary area in the south, and of the overlying Glen Herring Shale largely do not contain Na-mica.

(2) The WKM X-ray peaks at $10 \AA$ and $5 \AA$ in these Na-mica rich samples can be deconvoluted from the composite peaks with a three-peak fitting procedure. The fitted $\mathrm{FWHM}_{10 \AA}{ }^{*}$ and $\mathrm{FWHM}_{5 \AA}{ }^{*}$ obtained are similar to the FWHM in samples poor in $\mathrm{Na}$-mica, and thus can be used for determination of the grade of metamorphism.

(3) The MC Formation shows a metamorphic zoning, with the highest, "epimetamorphic" grades in the Dromedary area in the southern part, and the lowest, medium to high anchimetamorphic grades in the central part - notably in an anticlinal zone extending from Nullagine to the Blue Spec mine - and the overlying Glen Herring Shale. A relationship with early, i.e. growth folding, is suggested.

(4) The low $b_{0}$ lattice parameter of the WKMs indicates a very low metamorphic $\mathrm{P} / \mathrm{T}$ gradient.

(5) Identification of a distinct break in metamorphic grade between the MC Formation and the overlying Glen Herring Shale largely depends on whether or not deconvolution is applied. Its absence in the first case would suggest that the metamorphism of the MC Formation in part has taken place after deposition of part or all of the Fortescue Group and possibly an intermediate position of the Glen Herring Shale unit between the MC Formation and the Fortescue Group at this particular locality, whereas its presence implies that the metamorphism of the MC Formation largely has taken place before deposition of the Fortescue Group.

(6) The protolith of the Na-mica rich metasediments of the MC Formation was strongly Al-enriched and K-depleted with respect to its presumably granitic-tonalitic source rock. It was rich in kaolinite, and was subsequently enriched in Na by reaction with a Na-rich, low intermediate-pH solution, possibly seawater or Na-rich lake water.

\section{Acknowledgements}

This study forms part of the Earth's Earliest Basin project of Utrecht University in cooperation with researchers from other universities. We gratefully acknowledge the defrayal of the expenses of fieldwork in the Pilbara by the Dutch Foundation "Stichting Dr. Schürmannfonds", grants nos 2000/14 and 2002/10. Mrs. Esther Shani prepared the samples and ran the X-ray traces. The referees, Dr. Covadonga Brime and Prof. Péter Arkai, materially helped to improve the manuscript by perspicuously pointing out unclear points and insufficiently substantiated statements.

\section{Appendix A. Choice of the ${ }^{\circ} 2 \theta$ locking angle of the MNKM peak}

\section{A.1. Deconvolution of the $10-\AA$ WKM peak}

Fig. 8 shows the effect of the locking angle $2 \theta$ of the MNKM peaks on the FWHM of the fitted WKM at $10 \AA$ (hence: $\mathrm{FWHM}_{10 \AA}{ }^{*}$ ) 


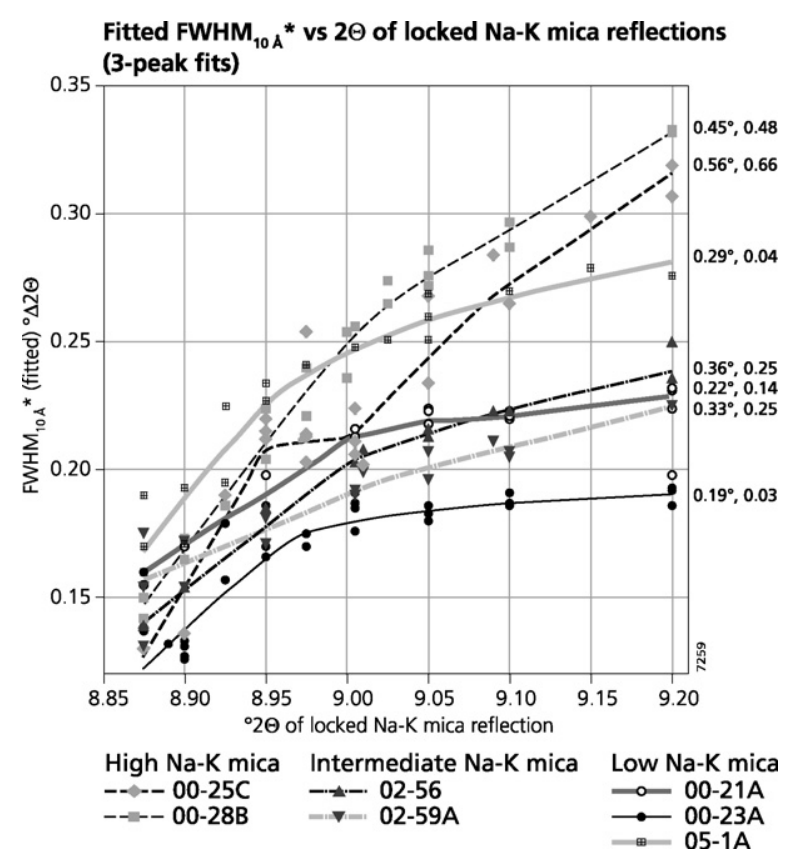

Fig. 8. Effect of the locking angle $2 \theta$ of the MNKM peaks on the FWHM of the fitted WKM at $10 \AA\left(\mathrm{FWHM}_{10 \AA} \AA^{*}\right)$ for four MNKM rich and three MNKM poor samples using three-peak deconvolution. The figures at the right-hand end of the curves are the single-peak fitting FWHM of the composite 10 - ̊ peak and the ratio of the intensity of the Na-K plateau at 4.89-4.90 ̊ to that of the WKM peak at $5 \AA$; this ratio indicates the approximate content of Na-micas. All peaks locked unless otherwise indicated.

for four MNKM rich and three MNKM poor samples; the ratio of the intensity of the MNKM plateau to that of the WKM peak at $5 \AA$ indicates the approximate content of Na-micas.

The paragonite peaks generally show low-angle tails, possibly an artifact of the asymmetric peaks used; fits with MNKM peaks showing strong high-angle tails are associated with anomalously broad $\mathrm{FWHM}_{10 \AA}{ }^{*}$ values and have been disregarded. Compared to the FWHM of the composite peak (indicated in the right-hand margin), locking a MNKM peak reduces the fitted $\mathrm{FWHM}_{10 \AA}{ }^{*}$ of the Na-mica rich samples relative to the single-peak fitting FWHM $_{10 \AA}$ much more than that of the Na-mica poor samples.

Lowering the $2 \theta$ locking angle of the MNKM peak from $9.10^{\circ}$ to $9.00^{\circ}$ narrows $\mathrm{FWHM}_{10 \AA}{ }^{*}$ of the WKM peak. This effect is proportional to the Na-mica content - small in the traces poor in Na-mica, and major in the traces rich in MNKM (expressed by flat and steep slopes of the curves in Fig. 8, respectively). It also gradually enhances the intensity and/or narrows the FWHM MNKM $^{*}$ of the fitted MNKM peak itself, especially of the weak and broad peaks in the Na-mica poor traces such as 00-21A, 00-23A, and 05-1 A, and in some Na-mica rich traces such as $00-25 \mathrm{C}$, whereas in some of the Na-mica richer traces $02-56,02-59$ and $00-28 \mathrm{~B}$ both change very little. This difference in behaviour between samples with intermediate Na-mica contents, such as 02-56 and 02-59A, and samples with a similarly broad composite peak of $0.29^{\circ} \Delta 2 \theta$ but low Namica content, such as $05-1 \mathrm{~A}$, shows that the effect of the fitting procedure on the WKM peaks is smaller in the Na-mica poor than in the Na-mica rich samples.

Further reduction of the angular separation between the locked MNKM peak and the WKM peak at ca. $8.84^{\circ} 2 \theta$ to less than $0.1^{\circ}$ by locking the MNKM peak at progressively lower $2 \theta$ angles of $\leq 8.95^{\circ} 2 \theta$ causes enhanced reduction in both the intensity (hence $I_{10 \AA}{ }^{*}$ ) and the FWHM ${ }_{10 \AA}{ }^{*}$ of the fitted WKM peak, whereby the latter narrows at a much steeper rate for the Na-mica rich than for the Na-mica poor samples; it also enhances the intensity of the MNKM peak and - in all except the most Na-mica rich samples $00-28 \mathrm{~B}$ and $00-25 \mathrm{C}-$ also reduces its fitted $\mathrm{FWHM}_{\mathrm{MNKM}}{ }^{*}$. As the MNKM

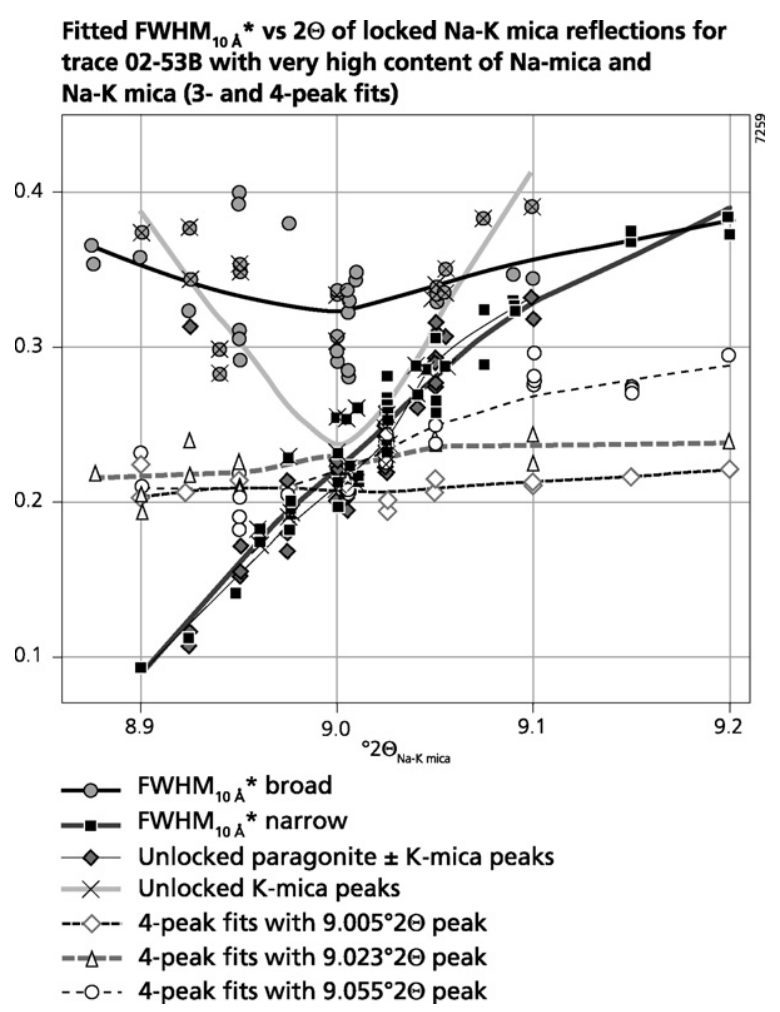

Fig. 9. Effect of the locking angle $2 \theta$ of the MNKM peaks on the FWHM of the fitted WKM at $10 \AA\left(\mathrm{FWHM}_{10 \AA}{ }^{*}\right)$ for sample $02-53 \mathrm{~B}$, the sample with the highest content of Na-mica found and with a distinct regular MNKM peak The drawn curves and the curves with long dashes respectively show the narrow and broad FWHM $10 \AA$ values for three-peak fittings with MNKM peaks locked at angles $\leq 9.05^{\circ} 2 \theta$. The curve with short dashes shows $\mathrm{FWHM}_{10 \AA}{ }^{*}$ for three-peak fits with the paragonite peak at $9.17^{\circ} 2 \theta$ unlocked and allowed to migrate to a somewhat lower $2 \theta$ angle. The three curves with intermediate dashes show $\mathrm{FWHM}_{10 \AA}{ }^{*}$ for four-peak fits with an additional MNKM peak locked at $9.005^{\circ}, 9.023^{\circ}$, and $9.055^{\circ} 2 \theta$. All peaks locked unless otherwise indicated. Fits with reliability $<97.40 \%$ omitted.

peak is locked at small ${ }^{\circ} 2 \theta$ angles, approaching the WKM position at ca. $8.84^{\circ} 2 \theta(10 \AA)$, the $\mathrm{FWHM}_{10 \AA}{ }^{*}$ values show a marked scatter, and become implausibly narrow, $0.10-0.19^{\circ} \Delta 2 \theta$ at locking angles of $\leq 8.90^{\circ} 2 \theta$ for all the samples. We have therefore adopted a locking angle of $9.005^{\circ} 2 \theta$ for the $\mathrm{Na} / \mathrm{K}$ mica, corresponding to a $0.5 / 0.5$ $\mathrm{Na} / \mathrm{K}$ mica composition.

Deconvolution of sample with exceptionally high content of $\mathrm{Na}$ mica. Sample 02-53B has the highest content of Na-mica found: its composite peak has a broad maximum from $8.87^{\circ}$ to $9.00^{\circ} 2 \theta$, an intensity ratio $I_{4.89-4.90 \AA} / I_{5.0 \AA}$ of 0.84 , and a distinct regular MNKM peak. Peak fitting with three locked peaks does not produce unequivocal results (Fig. 9), indicating that it is insufficiently constrained by three locked peaks: notably at low-angle locking positions of the MNKM peak $\left(\leq 9.05^{\circ} 2 \theta\right)$, the fitted 10 - $\AA$ peaks show strong bimodality and scatter in both $I_{10 \AA}{ }^{*}$ and $\mathrm{FWHM}_{10 \AA}{ }^{*}$, indicating that the peak fitting is insufficiently constrained by three locked peaks. 3-Peak fitting with MNKM peaks locked at small angles of $\leq 9.05^{\circ} 2 \theta$ generates two populations of very different $\mathrm{FWHM}_{10 \AA}$ * values, both with similarly high peak-fitting reliabilities, one (a) with broad $\mathrm{FWHM}_{10 \AA}{ }^{*}$ of $0.29-0.36^{\circ} \Delta 2 \theta$, high intensity, and usually high-angle tails, associated with comparatively weak, mostly near-symmetric MNKM ${ }^{*}$ peaks (Fig. 10a), and the other (b) with narrow $\mathrm{FWHM}_{10 \AA} \AA^{*}$, low intensity, and symmetric or with weak

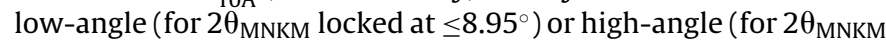
locked at $>8.95^{\circ}$ ) tails, associated with strong, broad, largely symmetric MNKM ${ }^{*}$ peaks (Fig. 10b).

Leaving the WKM peaks unlocked, the weak narrow nearsymmetric $\mathrm{WKM}^{*}$ peaks generated with $2 \theta_{\text {MNKM }}$ locked at 

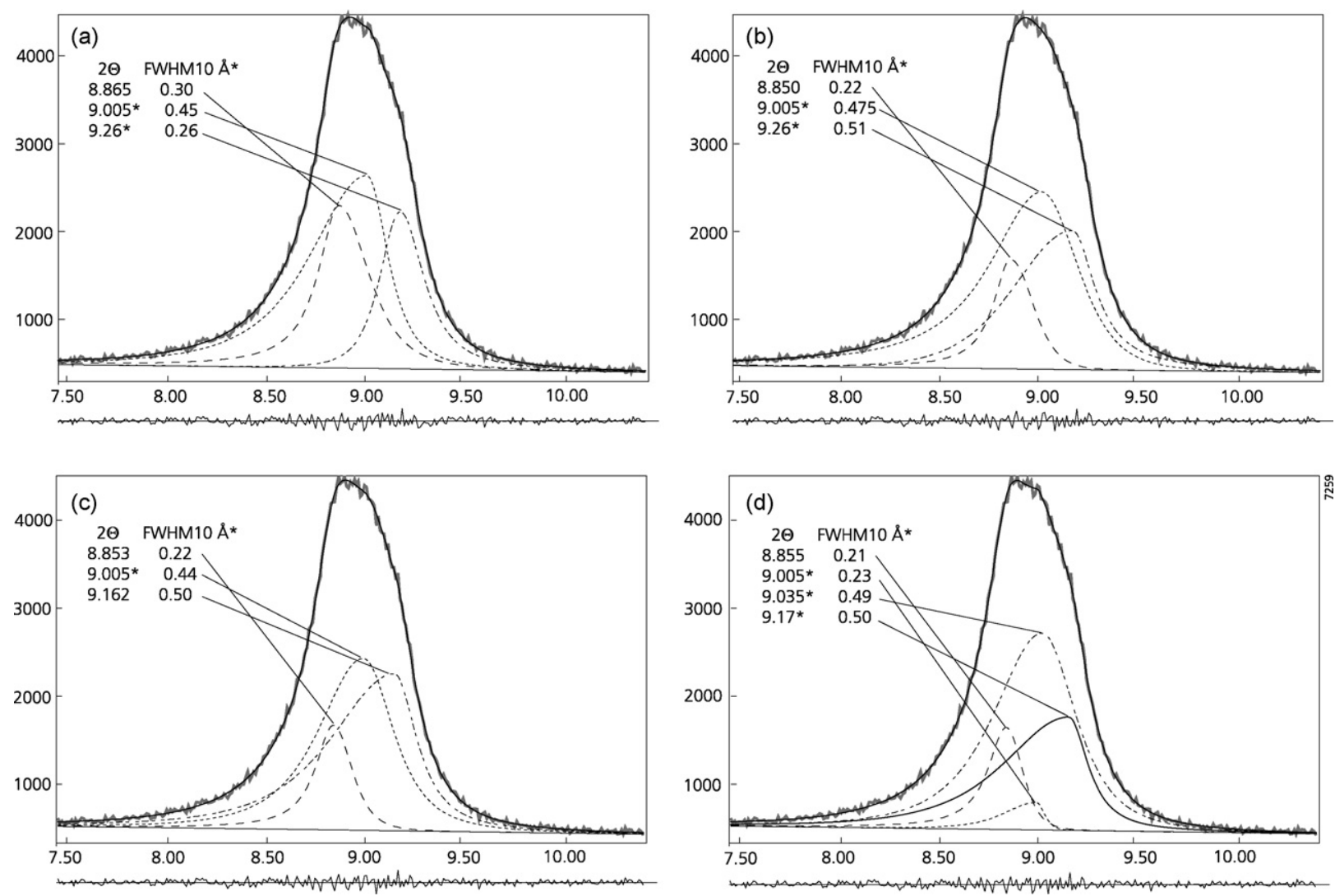

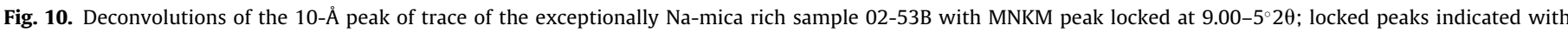

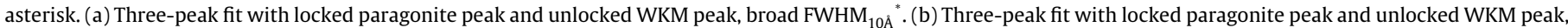

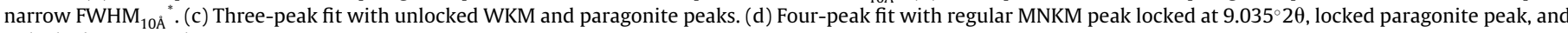
unlocked WKM peak.

8.96-9.03 $2 \theta$ mainly have maxima at $8.85-8.859^{\circ} 2 \theta$ and are associated with strong near-symmetric MNKM, and to a lesser extent with maxima at $8.86-8.876^{\circ} 2 \theta$ in association with unusually strong paragonite $^{*}$ peaks ( $2 \theta_{\text {MNKM }}$ locked at $9.01-9.03^{\circ} 2 \theta$ ). In contrast, fitting at lower $2 \theta_{\text {MNKM }}\left(<8.96^{\circ} 2 \theta\right)$ MNKM lock angles produces mainly strong and broad $\mathrm{WKM}^{*}$ peaks with high-angle tails and maxima at $8.86-8.875^{\circ} 2 \theta$, associated with notably weaker symmetric $\mathrm{MNKM}^{*}$ peaks (curve with short dashes in Fig. 9). Both the asymmetry of these broad $\mathrm{WKM}^{*}$ peaks and the migration of their peak maximum to higher $2 \theta_{\mathrm{WKM}}$ angles reflect incorporation of poorly-'crystalline' or K-rich MNKMs, and indicate that the narrow $\mathrm{FWHM}_{10 \AA}{ }^{*}$ values from the weaker symmetric peaks represent the Kübler index of the WKM. These scattering effects can be minimized by leaving the paragonite peak unlocked (Fig. 10c); in this case we obtain similar fitted FWHM $_{10 \AA}{ }^{*}$ values of $0.21-0.23^{\circ} \Delta 2 \theta$ for a MNKM peak locked at 9.00-9.02 $2 \theta$ (curve with long dashes in Fig. 9).

Locking an additional MNKM peak at $9.023^{\circ} 2 \theta(9.80 \AA \mathrm{K} \alpha)$ equivalent to the distinct regular MNKM 004 reflection observed at $18.11^{\circ} 2 \theta(4.90 \AA \mathrm{K} \alpha)$, i.e. four-peak fits (Fig. 10d), virtually eliminates the effect of the locking position of the other MNKM peak on $\mathrm{FWHM}_{10 \AA}{ }^{*}$ (curve with long and short dashes), and corroborates these $\mathrm{FWHM}_{10 \AA} \AA^{*}$ values of $0.21-0.23^{\circ} \Delta 2 \theta$, intersecting the 3-peak fitting curve at a similar fitted $\mathrm{FWHM}_{10 \AA}{ }^{*}$ values of $0.22-0.23^{\circ} \Delta 2 \theta$ (Fig. 9). 4-Peak fits with a fourth locked MNKM peak at $9.035^{\circ} 2 \theta$ and the other MNKM peak locked at 8.95-9.10 $2 \theta$ on four further samples with distinct regular MNKM peaks at ca. $18.10^{\circ} 2 \theta(00-28 \mathrm{~A}$, $02-80$ ) or both 006 at $27.41-27.44^{\circ} 2 \theta / 3.251-3.254 \AA$ and 0.0 .10 at 46.26-46.38 $2 \theta / 1.960-1.956 \mathrm{~K}_{1}(02-37 \mathrm{~A}, 02-50)$ also give fitted
$\mathrm{FWHM}_{10 \AA} \AA^{*}$ values within $0.02^{\circ} \Delta 2 \theta$ of those from 3-peak fits with MNKM locked at $9.005^{\circ} 2 \theta$.

\section{A.2. Deconvolution of the 5- $\AA$ WKM peak}

Rather than adopting the $2 \theta_{\text {MNKM }}$ locking angle of $18.065^{\circ} 2 \theta$ corresponding to a $0.5 / 0.5 \mathrm{Na} / \mathrm{K}$ composition of the MNKM, we have assessed the maximum convergence of the traces of samples with different content of Na-mica for three areas, each with probably a very restricted range of metamorphic grades, finding optimal convergences at $2 \theta_{\mathrm{MNKM}}$ lock angles of $17.98-18.00^{\circ}$. However, since the change in $\mathrm{FWHM}_{5 \AA}{ }^{*}$ for a given angular change in the lock angle $2 \theta_{\text {MNKM }}$ is approximately only half that in $\mathrm{FWHM}_{10 \AA}{ }^{*}$, the difference between $\mathrm{FWHM}_{5 \AA}{ }^{*}$ as fitted with $2 \theta_{\mathrm{MNKM}}$ at $18.00^{\circ}$ and at $18.065^{\circ}$, both listed in Table 1 , is rather minor, amounting to more than $0.01^{\circ} \Delta 2 \theta$ in only very few traces (notably the most Namica rich sample 02-53B, and some samples from the Glen Herring Shale).

We have opted for this locking angle of $2 \theta_{\mathrm{MNKM}}=18.00^{\circ}$, which also is close to a compromise between $2 \theta_{\mathrm{MNKM}}=18.065^{\circ} 2 \theta$ corresponding to a $50 / 50 \mathrm{Na} / \mathrm{K} \mathrm{MNKM}$ composition and $17.91^{\circ} 2 \theta$ - at an angular separation of $0.17^{\circ} \Delta 2 \theta$ with the WKM position at $17.74 \circ 2$ as adopted for the deconvolution of the $10-\AA$ peak. Note that deconvolution of the WKM 5- $\AA$ reflections requires the additional selection of the chlorite 003 reflection at ca. $4.72 \AA$ $\left(18.80^{\circ} 2 \theta \mathrm{K} \alpha\right)$, in view of its usually poor resolution from the paragonite reflection at $4.82 \AA\left(18.40^{\circ} 2 \theta \mathrm{K} \alpha\right)$ and the consequent need to choose the background at its high-angle side, at ca. $19.3^{\circ} 2 \theta$. Since in $\mathrm{AD}$ traces, the 003 reflection of smectite at $5 \AA$ 
enhances and sharpens the WKM peak, we have carried out the deconvolutions of the 5- $\AA$ peaks on the traces of the EG-solvated slides.

\section{References}

Árkai, P., 1991. Chlorite crystallinity: an empirical approach and correlation with illite crystallinity, coal rank and mineral facies as exemplified by Paleozoic and Mesozoic rocks of northeast Hungary. J. Metamorphic Geol. 9, 723-734.

Árkai, P., Sassi, F.P., Sassi, R., 1995. Simultaneous measurements of chlorite and illite crystallinity: a more reliable tool for monitoring low- to very low grade metamorphism in metapelites. A case study from the Southern Alps (NE Italy). Eur. J. Mineral. 7, 1115-1128.

Bagas, L., 2005. Geology of the Nullagine 1:100 000 Sheet. Geological Survey of Western Australia, Perth, 33 pp.

Bagas, L., Beukenhorst, O., Hos, K., 2004a. Nullagine, W.A. Sheet 2954. Western Australia Geological Survey (1:100 000 Geological Series).

Bagas, L., Farrell, T.R., Nelson, D.R., 2004b. The Age and Provenance of the Mosquito Creek Formation, Western Australia. Western Australia Geological Survey, Annual Review 2003-04. Western Australia Geological Survey, pp. 62-70.

Bagas, L., Bierlein, F.P., Bodorkos, S., Nelson, D.R., 2008. Tectonic setting, evolution and orogenic gold potential of the late Mesoarchaean Mosquito Creek Basin, North Pilbara Craton, Western Australia. Precambrian Res. 160, 237-244.

Battaglia, S., Leoni, L., Sartori, F., 2004. The Kübler index in late diagenetic to lowgrade metamorphic pelites: a critical comparison of data from $10 \AA$ and $5 \AA$ peaks. Clays Clay Miner. 52 (1), 85-105.

Blake, T.S., 1993. Late Archean crustal extension, sedimentary basin formation, flood basalt volcanism and continental rifting: the Nullagine and Mount Jope Supersequences, Western Australia. Precambrian Res. 60, 185-241.

Bossière, G., Menegazzo-Vitturi, L., Sassi, F.P., 1979. Caractères géobarométriques du crystallophyllien epimétamorphique anté-alpin de Grande Kabylie (Algérie). Bull. Minéral. 102, 55-60.

Brime, C., Castro, M., Luz Valín, M., 2002. Recognizing illitization progress from diagenesis to very low-grade metamorphism in rocks of the Cantabrian Zone (Spain). Schweiz. Mineral. Petrogr. Mitt. 82, 211-219.

Brown, G., Brindley, G.W., 1980. X-ray diffraction procedures for clay mineral identification. In: Brindley, G.W., Brown, G. (Eds.), Crystal Structures of Clay Minerals and their X-ray Identification. Mineralogical Society Monograph No. 5. Mineralogical Society, London, pp. 305-359.

Fettes, D.J., Graham, C.W., Sassi, F.P., Scolari, A., 1976. The lateral spacing of potassic white micas and facies series variation across the Caledonides. Scott. J. Geol. 12 (3), 227-236.

Frey, M., 1970. The step from diagenesis to metamorphism in pelitic rocks during Alpine orogenesis. Sedimentology 15, 261-279.

Frey, M., 1974. Alpine metamorphism of pelitic and marly rocks of the Central Alps. Schweiz. Mineral. Petrogr. Mitt. 54 (2/3), 489-506.

Frey, M., 1978. Progressive low-grade metamorphism of a black shale formation, Central Swiss Alps, with special reference to pyrophyllite and margarite bearing assemblages. J. Petrol. 19 (1), 95-135.

Garrels, R.M., Christ, C.L., 1965. Solutions, Minerals, and Equilibria. Harper \& Row, New York, 450 pp.

Guggenheim, S., Bain, D.C., Bergaya, F., Brigatti, M.F., Drits, V.A., Eberl, D.D., Formoso, M.L.L., Galán, E., Merriman, R.J., Peacor, D.R., Stanjek, H., Watanabe, T., 2001. Report of the Association Internationale pour l'Étude des Argiles (AIPEA) nomenclature committee for 2001: order, disorder and crystallinity in phyllosilicates and the use of "crystallinity index". Clays Clay Miner. 50 (3), 406-409.

Guidotti, C.V., Sassi, F.P., 1976. Muscovite as a petrogenetic indicator mineral in pelitic schists. Neues Jahrbuch Mineral. Abh. 127, 97-142.

Guidotti, C.V., Sassi, F.P., 1986. Classification and correlation of metamorphic facies series by means of muscovite $b_{0}$ data from low-grade metapelites. Neues Jahrbuch Mineral. Abh. 153 (3), 363-380.

Guidotti, C.V., Mazzoli, C., Sassi, F.P., Blencoe, J.G., 1992. Compositional controls on the cell dimensions of $2 \mathrm{M}_{1}$ muscovite and paragonite. Eur. J. Mineral. 4, 283-297.

Hickman, A.H., 1975. Geology of the Pilbara Block and its Environs. Geological Survey of Western Australia, Bulletin 127, 268 pp.

Hickman, A.H., 1984. Archaean diapirism in the Pilbara Block, Western Australia In: Kröner, A., Greiling, R. (Eds.), Precambrian Tectonics Illustrated. Schweizerbartsche Verlagsbuchhandlung, Stuttgart, pp. 113-127.

Jaboyedoff, M., Kübler, B., Sartori, M., Thélin, Ph., 2000. Basis for meaningful illite crystallinity measurements: an example from the Swiss Prealps. Schweiz. Mineral. Petrogr. Mitt. 80, 75-83.

Kisch, H.J., 1990. Calibration of the anchizone: a critical comparison of illite 'crystallinity' scales used for definition. J. Metamorphic Geol. 8, 31-46.

Kisch, H.J., 1991. Illite crystallinity: recommendations on sample preparation. Xray diffraction settings, and interlaboratory samples. J. Metamorphic Geol. 9, 665-670.

Kisch, H.J., Sassi, R., Sassi, F.P., 2006. The $b_{0}$ lattice parameter and chemistry of phengites from HP/LT metapelites. Eur. J. Mineral. 18, 207-222.

Kubler, B., 1968. Évaluation quantitative du métamorphisme par la cristallinité de l'illite. État des progrès réalisés ces dernières années. Bull. Centre Rech. Pau SNPA 2 (2), 385-397.

Livi, K.J.T., Veblen, D.R., Ferry, J.M., Frey, M., 1997. Evolution of 2:1 layered silicates in low-grade metamorphosed Liassic shales of Central Switzerland. Metamorphic Geol. 15, 323-344.

Livi, K.J.T., Christidis, G.E., Árkai, P., Veblen, D.R., 2008. White mica domain formation: a model for paragonite, margarite, and muscovite formation during prograde metamorphism. Am. Mineral. 93, 520-527.

Moore, D.M., Reynolds, R.C., 1997. X-ray Diffraction and the Identification and Analysis of Clay Minerals, 2nd edition. Oxford University Press, Oxford, 378 pp.

Nelson, D.R., 2002. Compilation of Geochronology Data, 2001. Western Australia Geological Survey, Record 2002/2, 282 pp.

Nijman, W., Clevis, Q., De Vries, S.T., submitted for publication. The waning stage of a Greenstone Belt: the Mesoarchaean Mosquito Creek Basin of the East Pilbara, W Australia. Precambrian Research.

Sassi, F.P., Scolari, A., 1974. The $b_{0}$ value of the potassic white micas as a barometric indicator in low-grade metamorphism of pelitic schists. Contr. Mineral. Petrol. 45, 143-152.

Stern, W.B., Mullis, J., Rahn, M., Frey, M., 1991. Deconvolution of the first "illite" basal reflection. Schweiz. Mineral. Petrogr. Mitt. 71, 453-462.

Theye, T., Seidel, E., 1991. Petrology of low-grade high-pressure metapelites from the External Hellenides (Crete, Peloponnese). A case study with attention to sodic minerals. Eur. J. Mineral. 3, 343-366.

Van Kranendonk, M.J., Hickman, A.H., Smithies, R.H., Williams, I.R., Bagas, L., Farrell, T.R., 2006. Revised Lithostratigraphy of Archean Supracrustal and Intrusive Rocks in the northern Pilbara Craton, Western Australia. Geological Survey of Western Australia, Record 15, 57 pp.

Wang, H., Stern, W.B., Frey, M., 1995. Deconvolution of the X-ray "Illite" 10 Å complex: a case study of Helvetic sediments from eastern Switzerland. Schweiz. Mineral. Petrogr. Mitt. 75, 187-199. 